\title{
Transient Receptor Potential Ankyrin Type-1 Channels as a Potential Target for the Treatment of Cardiovascular Diseases
}

\author{
Song Gao ${ }^{1 \dagger}$, Keneilwe Kenny Kaudimba ${ }^{1+}$, Shanshan Guo ${ }^{1}$, Shuang Zhang ${ }^{1,2}$, \\ Tiemin Liu ${ }^{1,3 *}$, Peijie Chen ${ }^{1 *}$ and Ru Wang ${ }^{1 *}$
}

${ }^{1}$ School of Kinesiology, Shanghai University of Sport, Shanghai, China, ${ }^{2}$ Institute of Sport Science, Harbin Sport University, Harbin, China, ${ }^{3}$ State Key Laboratory of Genetic Engineering, Institute of Metabolism and Integrative Biology, Human Phenome Institute, Department of Endocrinology and Metabolism, and School of Life Sciences, Zhongshan Hospital, Fudan University, Shanghai, China

OPEN ACCESS

Edited by:

Ying Mei Zhang,

Zhongshan Hospital, Fudan

University, China

Reviewed by:

Alexander Dietrich,

Ludwig Maximilian University

of Munich, Germany

Jun Ren,

University of Washington,

United States

*Correspondence:

Tiemin Liu

tiemin_liu@fudan.edu.cn

Peijie Chen

chenpeijie@sus.edu.cn

Ru Wang

wangru@sus.edu.cn

${ }^{\dagger}$ These authors have contributed equally to this work

Specialty section: This article was submitted to

Vascular Physiology,

a section of the journal

Frontiers in Physiology

Received: 19 January 2020 Accepted: 22 June 2020

Published: 30 July 2020

Citation:

Gao S, Kaudimba KK, Guo S, Zhang S, Liu T, Chen P and Wang $R$ (2020) Transient Receptor Potential Ankyrin Type-1 Channels as a Potential Target for the Treatment

of Cardiovascular Diseases.

Front. Physiol. 11:836.

doi: 10.3389/fphys.2020.00836
Cardiovascular disease is one of the chronic conditions with the highest mortality rate in the world. Underlying conditions such as hypertension, metabolic disorders, and habits like smoking are contributors to the manifestation of cardiovascular diseases. The treatment of cardiovascular diseases is inseparable from the development of drugs. Consequently, this has led to many researchers to focus on the search for effective drug targets. The transient receptor potential channel Ankyrin 1 (TRPA1) subtype is a non-selective cation channel, which belongs to the transient receptor potential (TRP) ion channel. Previous studies have shown that members of the TRP family contribute significantly to cardiovascular disease. However, many researchers have not explored the role of TRPA1 as a potential target for the treatment of cardiovascular diseases. Furthermore, recent studies revealed that TRPA1 is commonly expressed in the vascular endothelium. The endothelium is linked to the causes of some cardiovascular diseases, such as atherosclerosis, myocardial fibrosis, heart failure, and arrhythmia. The activation of TRPA1 has a positive effect on atherosclerosis, but it has a negative effect on other cardiovascular diseases such as myocardial fibrosis and heart failure. This review introduces the structural and functional characteristics of TRPA1 and its importance on vascular physiology and common cardiovascular diseases. Moreover, this review summarizes some evidence that TRPA1 is correlated to cardiovascular disease risk factors.

Keywords: TRPA1 channel, vascular physiology, atherosclerosis, heart failure, myocardial fibrosis, arrhythmia

\section{INTRODUCTION}

At present, the incidence of cardiovascular disease has increased significantly and has become a significant health issue of global concern (North and Sinclair, 2012; Alali et al., 2017). The rapid world economic growth has aggravated the double pressure of work coupled with unhealthy lifestyles, which increases the chance of being exposed to independent risk factors (Luan et al., 2019). Independent risk factors for cardiovascular diseases include smoking, diabetes, hypertension, dyslipidemia, and obesity (Guo et al., 2020; Wang R. et al., 2020). Long-term exposure to risk factors exacerbates the impacts of cardiovascular disease (Pei et al., 2014; Wu et al., 2019a). Common cardiovascular diseases include atherosclerosis, myocardial fibrosis, heart failure, and arrhythmia. Almost all cardiovascular diseases require long-term medication to correct their 
physiological and pathological changes (Huddy et al., 2013). However, the side effects of long-term medication should be addressed aggressively (Ramkumar et al., 2016). Treating arrhythmia with some antiarrhythmic drugs can cause bradycardia and atrioventricular block (Sardar et al., 2016). Furthermore, long-term use of cardiotonic drugs can cause arrhythmia in addition to gastrointestinal symptoms (Ward et al., 1983; Hamlin, 2007; Sala and Bellin, 2017; Ivanov and Lagunin, 2019). Therefore, it is particularly important to explore new drug targets for the treatment of cardiovascular diseases. The discovery of drug targets is the basis of new drug development. The discovery of a new drug target is a breakthrough in the development of a series of new drugs. Currently, the targets of cardiovascular diseases are updated constantly. Researchers started with the pathogenesis of cardiovascular diseases looking for key receptors, ion channels, and signaling pathways that mediate the formation of cardiovascular diseases as targets for drug development (Overington et al., 2006; Maclay and MacNee, 2013; Mokou et al., 2017). Common drug targets for cardiovascular diseases are Rho kinase (Shimokawa et al., 2016), M3 receptor in functional muscarinic acetylcholine receptor (Kovacevic et al., 2015; Rhoden et al., 2019), S1P signaling pathway (sphingosine 1-phosphate) (Yung et al., 2017), and miR-145 (Massy et al., 2017; Sahu et al., 2017).

Transient receptor potential (TRP) channels are widely regarded as drug targets (Moran, 2018). TRP was first discovered when studying the visual conduction system of Drosophila melanogaster (Katz et al., 2013). In subsequent studies, more than 50 channel members of this family have been found from yeast, insects, fish, and mammals, of which more than 30 were found in mammals (Moran et al., 2004; Vriens et al., 2004; Nilius and Owsianik, 2011). Based on the differences in amino acid sequence homology of 33 TRP channels found in mammals, the TPR channels are divided into seven subfamilies, namely, TRPA, TRPC, TRPV, TRPM, TRPP, TRPML, and TRPN (Ramsey et al., 2006). Previous research has shown that members of the TRP family closely relate to cardiovascular disease (Ma et al., 2017). TRPV1 channel can regulate vascular smooth muscle and improve hypertension, causing heart dysfunction under cold exposure (Zhang et al., 2012; Shanks et al., 2019). The TRPV1 and TRPV4 channels are involved in the cardiovascular protection of hypoxia. TRPM7 is significantly upregulated in atrial fibroblasts from patients with atrial fibrillation (Yue et al., 2015). However, the role of TRPA1 in cardiovascular diseases is uncertain. In recent years, research on TRPA1 has been increasing, hence a close relationship between TRPA1 and cardiovascular diseases is established (Bodkin and Brain, 2011). Atherosclerosis causes chronic inflammation, and the activation of TRPA1 suppresses this inflammation (Bautista et al., 2006; Bonet et al., 2013). Moreover, some studies found that TRPA1 is also involved in the process of oxidative stress and myocardial fibrosis (Nilius and Szallasi, 2014; Wang et al., 2018).

In this review, researchers summarized the structure and the functions of TRPA1, which commonly uses agonists and inhibitors. Furthermore, the review summarizes the potential role of TRPA1 in regulating the pathophysiology of the cardiovascular system, including vascular physiology, atherosclerosis, myocardial fibrosis, heart failure, and arrhythmia (Table 1). Finally, this paper presents some evidence that TRPA1 is closely linked to cardiovascular disease risk factors.

\section{The Structure and Function of TRPA1}

TRP ion channel is a non-selective cation channel located on the cell membrane, which is essentially a tetrameric form of $\mathrm{Ca}^{2+}$ influx channel (Hardie and Minke, 1992; Hofmann et al., 2017). Minke et al. discovered TRP in visual cells of Drosophila for the first time when studying the Drosophila experiments that is related to visual conduction (Cosens and Manning, 1969). It was observed that TRP only induces transient $\mathrm{Ca}^{2+}$ influx after light stimulation, generating a transient potential (Kumar et al., 2015). The letter "A" in the TPRA subfamily represents ankyrin, which has only one member, TRPA1. Like other TRP channels, ankyrin is embedded in the cell membrane and has a six-time transmembrane structure. They have a stoma area between S5 and S6 for ions to enter and exit the cell membrane. The $\mathrm{N}$ terminus and $\mathrm{C}$ terminus of the channel protein are located inside the cell (Schaefer, 2005; MacPherson, 2007). TRPA1 has similar characteristics of ankyrin repeats at its $\mathrm{N}$ terminus, whereas other TRP subfamily ankyrin repeats have only three to four times (Bodkin and Brain, 2011; Benemei et al., 2013). Ankyrin repeats are 33 -amino-acid motifs that regulate the interaction between proteins. The cysteine residues in these repeats act as TRPA1 agonists covalently modifying the binding target (Dietrich et al., 2017). After TRPA1 activation, extracellular cations, such as $\mathrm{Na}^{+}$and $\mathrm{H}^{+}$, are increased, especially $\mathrm{Ca}^{2+}$ influx, thereby mediating a series of physiological responses (Story et al., 2003). The structure of TRPA1 is shown in Figure 1. TRPA1 is best known as a sensor for environmental irritants giving rise to somatosensory modalities, such as pain, cold, itch, and other protective responses. TRPA1 plays an vital role in the pathological process of cough, oxidative stress, and inflammation (Chen et al., 2013; Benemei et al., 2014; Kurganov et al., 2014; Nassini et al., 2014; Winter et al., 2017). Recent studies have found that TRPA1 activation articulates in pancreatic islets, gastrointestinal tract, heart, and blood vessels (Pozsgai et al., 2010; Kun et al., 2014). Activation of TRPA1 in islet $\beta$ cells can stimulate insulin secretion (Cao et al., 2012), in vascular cells it can improve endothelium-dependent diastolic function (Earley et al., 2009; Inoue et al., 2009), whereas in the intestine it can regulate the secretion of hunger hormones, GLP-1, and has effects on weight loss and regulating glucose and lipid metabolism (Derbenev and Zsombok, 2016). These studies concluded that TRPA1 might serve as a potential target to protect blood vessels and regulate metabolism.

TRPA1 is a non-selective cation channel and has the function of a receptor. TRPA1 channel activation includes multiple pathways. TRPA1 can be activated by a series of chemical stimuli, including cinnamaldehyde (Bandell et al., 2004), allicin (Bautista et al., 2005), allyl isothiocyanate (AITC) (Bandell et al., 2004; Jordt et al., 2004), ligustilide (Zhong et al., 2011), acrolein (Bautista et al., 2006), and nicotine (Andre et al., 2008; Talavera et al., 2009). In addition to exogenous agonists, recent studies found out that endogenous compounds released during tissue damage and oxidative stress can also activate 
TABLE 1 | Role of the TRPA1 channel in the cardiovascular system.

\begin{tabular}{|c|c|c|c|c|c|}
\hline Diseases & Animals & $\begin{array}{l}\text { Expression in } \\
\text { heart and } \\
\text { vasculature }\end{array}$ & Effects & Mechanisms & References \\
\hline & Male Sprague-Dawley rats & $\begin{array}{l}\text { Trigeminal root } \\
\text { ganglia neurons }\end{array}$ & $\begin{array}{l}\text { AITC (100 } \mu \mathrm{M} \text {, intranasal } \\
\text { administration) and acrolein ( } 30 \mu \mathrm{M} \text {, } \\
\text { intranasal administration) increase } \\
\text { cerebral blood flow, but the effect is } \\
\text { blocked by HC-030031 ( } 50 \mu \mathrm{M} \text {, } \\
\text { intranasal administration) }\end{array}$ & Neurogenic vasodilation & Kunkler et al., 2011 \\
\hline & $\begin{array}{l}\text { Male CD1, CGRP-/-, } \\
\text { TRPV1-/-, and TRPA1-/- } \\
\text { mice (8-12 weeks old) }\end{array}$ & - & $\begin{array}{l}\text { Cinnamaldehyde (1-30\%) increases the } \\
\text { blood flow, but not in HC-030031 } \\
\text { (100 mg/kg)-treated and TRPA1 } \\
\text { knockout mice }\end{array}$ & Neurogenic vasodilation & $\begin{array}{l}\text { Aubdool et al., } \\
2016\end{array}$ \\
\hline & Adolescent rats & Endothelial cells & $\begin{array}{l}\text { AITC }(15-60 \mu \mathrm{M}) \text { evokes graded } \\
\text { cerebral artery vasodilation }\end{array}$ & $\begin{array}{l}\text { Endothelium-dependent } \\
\text { vasodilation }\end{array}$ & Qian et al., 2013 \\
\hline & $\begin{array}{l}\text { CD1, CGRP-/-, TRPV1-/-, } \\
\text { and TRPA1-/- mice }\end{array}$ & - & $\begin{array}{l}\text { Cinnamaldehyde ( } 80-320 \mu \mathrm{M} / \mathrm{kg}) \\
\text { induces a transient hypotensive } \\
\text { response followed by a sustained } \\
\text { hypertensive response }\end{array}$ & Autonomic system reflexes & Pozsgai et al., 2010 \\
\hline \multirow[t]{2}{*}{ Atherosclerosis } & $\begin{array}{l}\text { Male C57BL/6, apoE-/- } \\
\text { and apoE-/-TRPA1-/- mice } \\
\text { (8 weeks old) }\end{array}$ & Macrophages & $\begin{array}{l}\text { AITC ( } 10 \text { mg/kg/day, } 4 \text { weeks, i.g.) } \\
\text { suppresses atherosclerosis; } \\
\text { HC-030031 ( } 10 \mathrm{mg} / \mathrm{kg} / \text { day, } 4 \text { weeks, } \\
\text { i.g.) and TRPA1 knockout exacerbate } \\
\text { atherosclerosis }\end{array}$ & $\begin{array}{l}\text { Cholesterol metabolism and } \\
\text { inflammation in macrophages }\end{array}$ & Zhao et al., 2016 \\
\hline & $\begin{array}{l}\text { Male C57BL/6, apoE-/-, } \\
\text { and apoE-/-TRPA1-/-mice } \\
\text { (6-8 weeks old) }\end{array}$ & Macrophages & $\begin{array}{l}\text { TRPA1-/-ApoE-/- mice showed a } \\
\text { significant increase in atherosclerosis } \\
\text { plaques; activation of TRPA1 by CIN } \\
\text { sharply reduced atherosclerosis } \\
\text { progression }\end{array}$ & Inflammation in macrophages & $\begin{array}{l}\text { Wang Q. et al., } \\
2020\end{array}$ \\
\hline & - & Cardiac fibroblasts & $\begin{array}{l}\text { Activating TRPA } 1 \text { with a specific } \\
\text { agonist AITC promoted the synthesis } \\
\text { and secretion of CGRP, as well as } \\
\text { intracellular } \mathrm{Ca}^{2+}\end{array}$ & $\begin{array}{l}\text { Increasing autocrine CGRP by } \\
\text { activating TRPA1 can } \\
\text { ameliorate cardiac fibrosis }\end{array}$ & Li et al., 2019 \\
\hline Heart failure & Male SD rats & $\begin{array}{l}\text { Cardiomyocytes } \\
\text { and dorsal root } \\
\text { ganglia cell }\end{array}$ & $\begin{array}{l}\text { The measured physiological response } \\
\text { to topical application of AITC to both } \\
\text { the lung and heart surface was blunted }\end{array}$ & $\begin{array}{l}\text { In vivo reduction of TRPA1 } \\
\text { expression was, in part, caused } \\
\text { by CHF-related tissue ischemia } \\
\text { and inflammation }\end{array}$ & Adam et al., 2019 \\
\hline \multirow[t]{2}{*}{ Arrhythmia } & $\begin{array}{l}\text { Female B6129 mice } \\
\text { (19-21 weeks old) and } \\
\text { TRPA1-/- mice } \\
\text { (21-28 weeks old) }\end{array}$ & - & $\begin{array}{l}\text { Acrolein (537 ppm, } 8 \text { times/4 weeks, } \\
\text { inhalation) increases heart rate } \\
\text { variability and myocardial desynchrony } \\
\text { in B6129 mice but not in TRPA1-/- mice }\end{array}$ & $\begin{array}{l}\text { Influence the autonomic } \\
\text { nervous system }\end{array}$ & $\begin{array}{l}\text { Thompson et al., } \\
2019\end{array}$ \\
\hline & $\begin{array}{l}\text { Female C57BL/6 and } \\
\text { TRPA1-/- mice } \\
\text { (15-30 weeks old) }\end{array}$ & - & $\begin{array}{l}\text { TRPA1 knockout decreases } \\
\text { acrolein-induced ( } 3 \text { ppm, } 3 \mathrm{~h} \text { ) heart rate } \\
\text { variability and arrhythmias }\end{array}$ & Cardiac autonomic function & $\begin{array}{l}\text { Kurhanewicz et al., } \\
2017,2018\end{array}$ \\
\hline
\end{tabular}


TABLE 1 | Continued

\begin{tabular}{|c|c|c|c|c|c|}
\hline Diseases & Animals & $\begin{array}{l}\text { Expression in heart and } \\
\text { vasculature }\end{array}$ & Effects & Mechanisms & References \\
\hline & $\begin{array}{l}\text { Male spontaneously } \\
\text { hypertensive rats } \\
\text { (18-20 weeks old) }\end{array}$ & - & $\begin{array}{l}\text { HC-030031 ( } 5 \text { mg/kg, i.p.) reduces } \\
\text { diesel exhaust ( } 32 \text { ppm, } 4 \text { h)-induced } \\
\text { and aconitine ( } 1.5 \mathrm{mg} / \mathrm{kg} \text {, i.p.)-induced } \\
\text { ventricular arrhythmias }\end{array}$ & $\begin{array}{l}\text { Restrains the activity of } \\
\text { sympathetic and autonomic } \\
\text { imbalance }\end{array}$ & Hazari et al., 2011 \\
\hline & $\begin{array}{l}\text { Male Sprague-Dawley rats } \\
\text { (15 weeks old) }\end{array}$ & - & $\begin{array}{l}\text { AITC ( } 30 \mathrm{mM}) \text { inhalation causes } \\
\text { bradycardia atrioventricular blockade } \\
\text { and prolonged PR intervals }\end{array}$ & Activates the vagus nerve & Hooper et al., 2016 \\
\hline
\end{tabular}

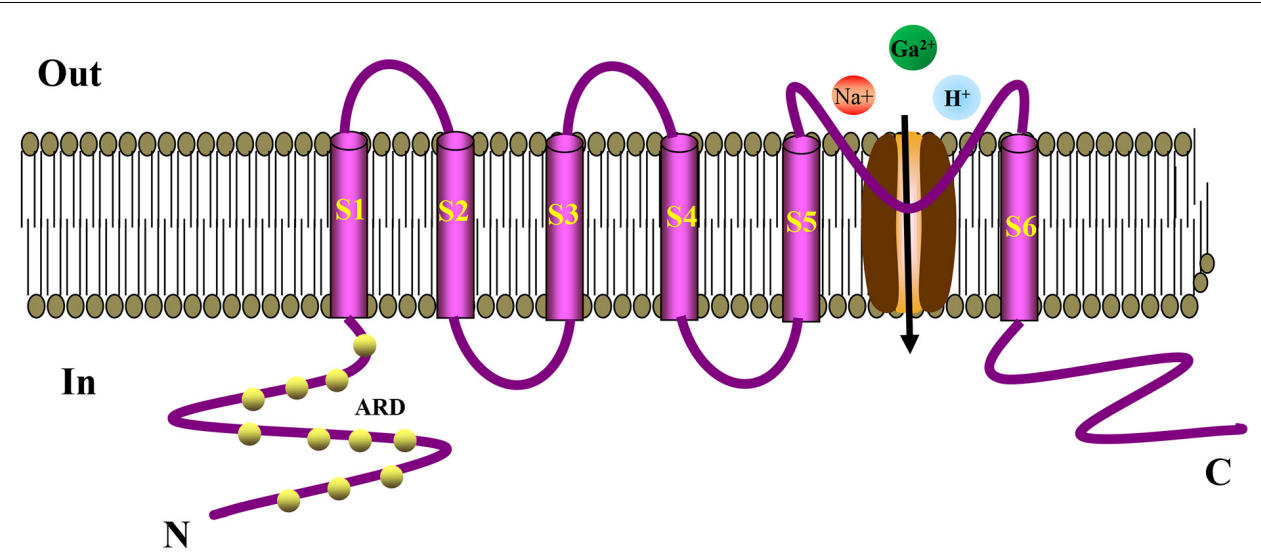

FIGURE 1 | Schematic diagram showing the structure of TRPA1 channel. The TRPA1 channel has a six-time transmembrane structure (S1-S6), and there is a minute opening between S5 and S6 for ions to enter and exit the cell membrane. The N-terminus and C-terminus of the channel protein are located inside the cell. The N-terminus has a large number of characteristic ankyrin repeats, and the cysteine residues in these repeats serve as binding targets for the covalent modification of TRPA1 agonists. TRPA1 can increase the influx of extracellular cations, such as $\mathrm{Na}^{+}, \mathrm{H}^{+}$, especially Ca ${ }^{2+}$, thereby mediating a series of physiological reactions. ARD, Ankyrin Repeat Domain.

TRPA1 channels, such as nitric oxide (NO) and hydrogen sulfide $\left(\mathrm{H}_{2} \mathrm{~S}\right)$ (Andersson et al., 2008; Eberhardt et al., 2014), hydrogen peroxide $\left(\mathrm{H}_{2} \mathrm{O}_{2}\right)$, 4-hydroxynon-enal (4-HNE), 4-oxoquinone (4-ONE), 4-hydroxyhexenal (4-HHE), and 15-deoxy-delta (12, 14)-prostaglandin J (2) (MacPherson et al., 2007b; Trevisani et al., 2007; Taylor-Clark et al., 2008). Besides, some synthetic compounds have also been reported, including ASP-7663 and Optovin (Kokel et al., 2013; Kojima et al., 2014). Low temperature is thought to activate the TRPA1 channel (Winter et al., 2017). However, TRPA1 is heat sensitive in snakes, lizards, and frogs (Kurganov et al., 2014). However, some agonists have a dual regulatory effect on TRPA1. For example, menthol activates TRPA1 at low concentrations and inhibits TRPA1 at high concentrations (MacPherson et al., 2006; Karashima et al., 2007; Alpizar et al., 2013). Table 2 lists commonly used TRPA1 agonists.

TRPA1's exogenous antagonists are mainly complex organic or inorganic compounds. Previous studies have found some TRPA1 antagonists, such as ruthenium red, gentamicin, camphor, and high concentration menthol, but these antagonists also have regulatory effects on other certain ion channels (such as TRPV1, TRPV2); therefore, it is not specific. At present, the specific antagonists of TRPA1 mainly include xanthine derivatives, such as HC030031 and its derivatives (McNamara et al., 2007), TCS5861528 (Wei et al., 2009), and GRC-17536 (Mukhopadhyay et al., 2014); and oxime derivatives, such as A-967079
(Chen et al., 2011) and AP-18 (Petrus et al., 2007; Defalco et al., 2010). The discovery of TRPA1 channel-specific antagonists has essential value for exploring the therapeutic uses of TRPA1. Therefore, researchers devote to finding TRPA1 channel-specific antagonists. Table 3 lists commonly used TRPA1 inhibitors.

\section{TRPA1 IN THE CARDIOVASCULAR SYSTEM}

\section{TRPA1 and Vascular Physiology}

The contraction and relaxation of blood vessels form blood pressure, which provides impetus for the blood flow. Vascular smooth muscle regulates the tension of blood vessels under the joint control of vasoconstrictor nerve fibers and vasomotor nerve fibers, which in turn affects changes in blood pressure and blood flow. Long-term abnormal blood pressure is a key factor that causes cardiovascular disease (Earley, 2012). Vascular endothelial cells and vascular smooth muscle cells play an essential role in maintaining normal vascular physiology. $K_{\mathrm{Ca}}$ channels in endothelial cells and $K_{\text {IR }}$ channels in cerebral arterial muscle cells are jointly mediated by vasodilation signals (Earley et al., 2009; Kohler and Ruth, 2010; Brunt et al., 2013). In addition, calcitonin gene-related peptides (CGRPs) secreted by vascular endothelial cells contribute to vasodilation (Aubdool et al., 2016). 
TABLE 2 | TRPA1 agonists.

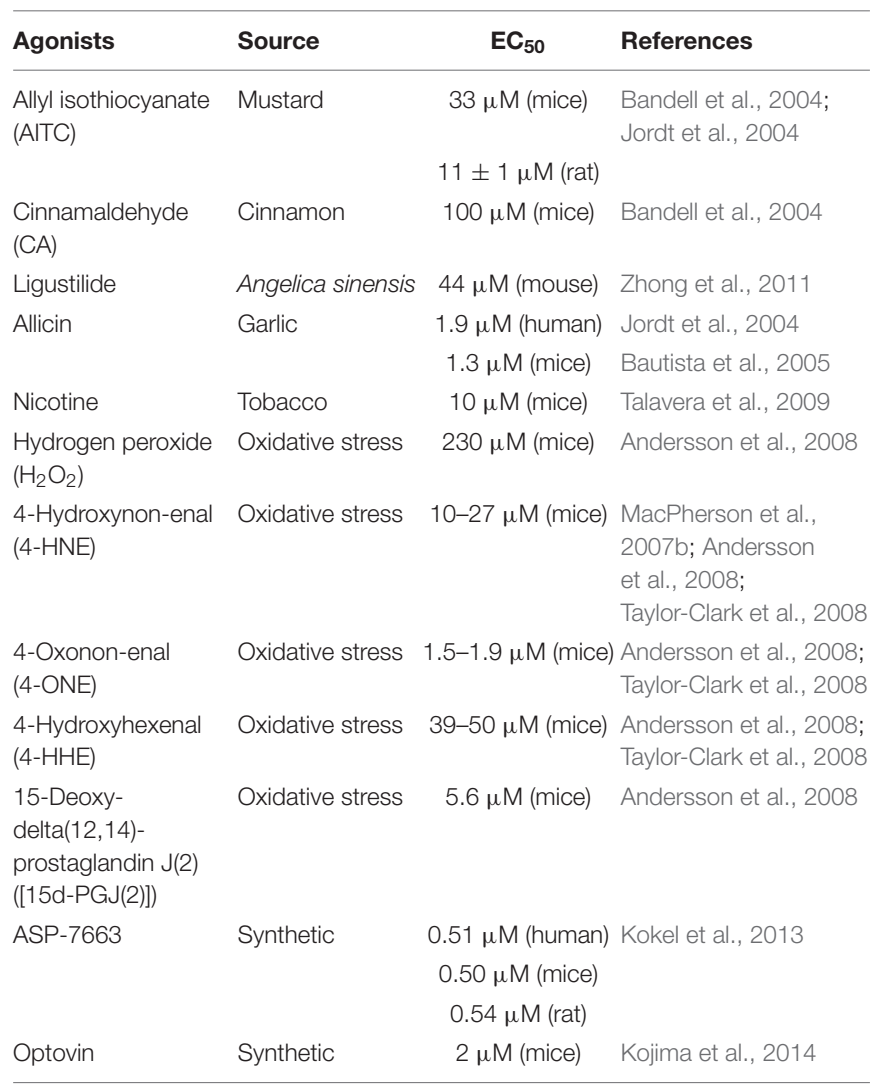

TABLE 3 | TRPA1 antagonists.

\begin{tabular}{|c|c|c|c|}
\hline Agonists & Structures & $I C_{50}$ & References \\
\hline HC-030031 & Xanthine derivative & $\begin{array}{c}6.2 \mu \mathrm{M} \text { (human) } 7.6 \\
\mu \mathrm{M} \text { (rat) }\end{array}$ & McNamara et al., 2007 \\
\hline GRC-17536 & Xanthine derivative & Not reported & $\begin{array}{l}\text { Mukhopadhyay et al., } \\
2014\end{array}$ \\
\hline TCS-5861528 & 3 Xanthine derivative & $14.3 \mu \mathrm{M}$ (human) & Wei et al., 2009 \\
\hline $\mathrm{AP}-18$ & Oxime & $\begin{array}{c}3.1 \mu \mathrm{M} \text { (human) } 8.8 \\
\mu \mathrm{M} \text { (rat) } 4.5 \mu \mathrm{M} \text { (mice) }\end{array}$ & $\begin{array}{l}\text { Petrus et al., 2007; } \\
\text { Defalco et al., } 2010\end{array}$ \\
\hline A-967079 & Oxime & $\begin{array}{c}0.067 \mu \mathrm{M} \text { (human) } \\
0.289 \mu \mathrm{M} \text { (rat) }\end{array}$ & Chen et al., 2011 \\
\hline
\end{tabular}

In recent years, studies have demonstrated that TRPA1 has been explored in the vascular system and it was discovered that it has a vital role in the regulation of vascular tone (Earley et al., 2010; Aubdool et al., 2014). Formaldehyde activates the sensitive TRPA1 channel, causing the endothelium-dependent mechanism of $\mathrm{Ca}^{2+}$ influx and mediating the relaxation of isolated rat superior mesenteric artery. However, the same effect has not been found in the aorta (Jin et al., 2019). 4-ONE leads to obvious vasodilation, but this effect is not reflected in TRPA1-/- mice (Graepel et al., 2011). Both AITC and cinnamaldehyde significantly increased blood flow in the skin of anesthetized wild-type mice, but had no significant effect on TRPA1 knockout mice (Pozsgai et al., 2010). In cerebral circulation, the TRPA1 channel occurs in endothelial cells, and it is concentrated in the junction site of the endothelium muscle. Activation of the TRPA1 channel causes $\mathrm{Ca}^{2+}$ influx, mediating smooth muscle cell hyperpolarization and endothelium-dependent vasodilation (Sullivan et al., 2015). A study pointed out that stimulation of the TRPA1 channel causes vasodilation in a graded cerebral artery which is also caused by endothelial cell $\mathrm{Ca}^{2+}$ signaling (Qian et al., 2013). One study revealed that TRPA1 inhibitors and endothelial destruction antagonize AITC-induced cerebral artery vasodilation. AITCinduced arterial dilatation was blocked by treatment with small and medium-conductivity $\mathrm{Ca}^{2+}$-activated $\mathrm{K}^{+}$channel blockers. Inwardly rectifying potassium channel treatment by blockers also blocked AITC-mediated vasodilation (Earley et al., 2009). The research indicated that $\mathrm{Ca}^{2+}$ influx via endothelial TRPA1 channels mediates cerebral artery vasodilation, which involves endothelial cell $\mathrm{Ca}^{2+}$-activated $\mathrm{K}^{+}$channels and smooth muscle inward rectification $\mathrm{K}^{+}$channels leading to hyperpolarization of cell membranes.

Other studies showed that the TRPA1 channel present in the peripheral vascular nerve mediates the chemical agonist through the mechanism of CGRP release, thereby mediating peripheral arterial vasodilation (Peixoto-Neves et al., 2019). The exogenous agonist of TRPA1 stimulates the release of CGRP and increases cerebral blood flow; this effect is blocked by TRPA1 and CGRP receptor antagonists (Kunkler et al., 2011; Aubdool et al., 2016).

The effect of TRPA1 activity on vascular physiology is also reflected in the regulation of blood pressure (Pazienza et al., 2014). Systemic administration of TRPA1 agonists will cause a transient hypotensive response, and then the heart rate and blood pressure continue to increase as a result of increased sympathetic nerve activity. Cinnamaldehyde relaxes the mesenteric artery in mice in a TRPA1-dependent manner (Pozsgai et al., 2010); however, the effect of intravenous administration of cinnamaldehyde on blood pressure is more complicated. The low dose of cinnamaldehyde causes the mesenteric artery to relax, which in turn causes a hypotensive response. The high dose of cinnamaldehyde causes a boosting response, which may involve the regulatory mechanism of the vagus nerve. Studies have indicated that vasodilation and antihypertensive effects are mediated by TRPA1 and TRPV1 (Ma et al., 2019). Vasodilation often uses propofol as an anesthetic, which in turn causes a hypotensive effect (Sinharoy et al., 2017). Currently, researchers knocked out the genes of TRPA1 and TRPV1 in mice, and the antihypertensive effect of propofol was significantly weakened (Sinha et al., 2015). However, after knocking out the mouse TRPV1 gene alone, the antihypertensive effect of propofol was not affected. Therefore, the TRPA1 ion channel, which mediates propofol-induced vasodilation, had little significance on TRPV1 ion channel. TRPA1 is a cold-stress cation channel that is activated at low temperatures $\left(<17^{\circ} \mathrm{C}\right)$. In low-temperature environments, skin blood vessels contract, and vasodilation occurs after continuous contraction. TRPA1 plays a vital role in changes in vascular tone mediated by low temperatures (Aubdool et al., 2014).

Therefore, TRPA1 causes vasodilation under the action of an agonist and increases blood flow, which in turn regulates blood pressure. TRPA1 channel regulates blood pressure in a 


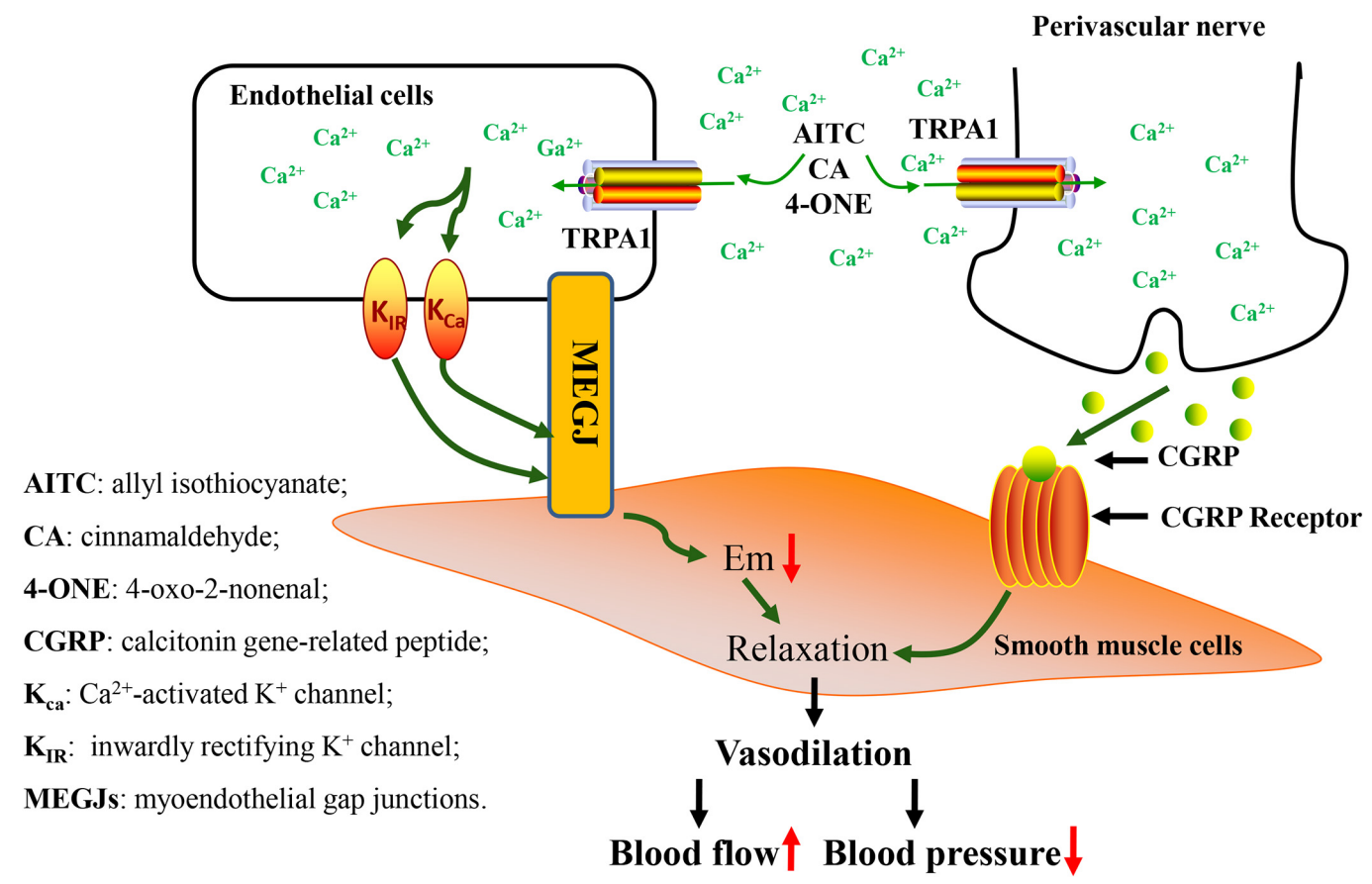

FIGURE 2 | Vascular physiological changes caused by activation of TRPA1 channel. Activation of the TRPA1 channel causes $\mathrm{Ca}^{2+}$ influx, leading to hyperpolarization of endothelial cell membranes. This change in potential causes hyperpolarization of smooth muscle cell membranes, causing relaxation of muscle cells. In addition, activation of the TRPA1 channel induces an increase in $\left[\mathrm{Ca}^{2+}\right]$, which leads to the release of the neuropeptide CGRP from perivascular nerve, thereby mediating vasodilation. Vasodilation causes changes in blood flow and blood pressure.

bidirectional manner, which is related to the dose of the agonist. In addition, the activation of the TRPA1 channel under lowtemperature environment causes changes in the tension of blood vessels (Figure 2). In conclusion, TRPA1 activity affects vascular function, but the exact role and significance of this channel in the cardiovascular system is yet to be determined.

\section{TRPA1 AND COMMON CARDIOVASCULAR DISEASES}

\section{TRPA1 and Atherosclerosis}

Atherosclerosis is one of the main reasons that lead to the causes of various cardiovascular diseases. The key initial factor of atherosclerosis is the accumulation of cholesterol ( $\mathrm{Yu}$ et al., 2016), which in turn causes the formation of atherosclerotic plaques. This plaque leads macrophages to trigger a chronic inflammatory response. Macrophages clear excess peripheral cholesterol and convert the intracellular cholesterol into highdensity lipoprotein (HDL) for excretion or storage. Macrophages play an essential role in the immune response of atherosclerosis, and the excessive intake of cholesterol into foam cells is the main reason for the formation of atherosclerosis (Lin et al., 2015). The outflow of cholesterol derived from oxidized lowdensity lipoprotein (oxLDL) is destroyed, and then the lipid accumulates in macrophages. When the lipid is overloaded and exceeds the metabolic capacity of macrophages, a large amount of lipids accumulate in the macrophages, which promotes the growth of blood vessel intima and the formation of necrotic nuclei, increasing the risk of plaque rupture. Furthermore, macrophages transform into foam cells, which further activates the inflammatory response and exacerbates the risk factors of plaque formation.

Cholesterol accumulation in macrophages determines lipid phagocytosis and cholesterol efflux. When the cholesterol content in the macrophages is too high, the macrophages will start the cholesterol efflux system and expel cholesterol from the cells to synthesize HDL. The main factors involved in cholesterol efflux are ATP binding cassette subfamily A member 1 (ABCA1) and ABCG1. Oxidative modified LDL causes lipid peroxidation of macrophages, which reduces the amount of HDL binding and causes cholesterol outflow disorder. TRPA1 expression in macrophage foam cells in the atherosclerotic aorta of apolipoprotein E-deficient [apoE (-/-)] mice was increased. Administration of the TRPA1 channel antagonist HC030031 or knockout of the TRPA1 [TRPA1 (-/-)] gene in apoE (-/-) mice can exacerbate atherosclerotic lesions, hyperlipidemia, and systemic inflammation (Zhao et al., 2016). Moreover, treatment with allyl isothiocyanate (AITC, TRPA1 agonist) can inhibit the progression of atherosclerosis in apoE (-/-) mice, but the TRPA1 (-/-) gene knockout atherosclerosis has no effect on sclerotic mice. Mouse macrophages showed that TRPA1 channels were activated by oxidized low-density lipoprotein (oxLDL). TRPA1 antagonists or knocking out the TRPA1 gene will exacerbate OxLDL-induced lipid accumulation in macrophages. Whereas inhibiting TRPA1 activity damages cholesterol efflux 
by downregulating the ATP binding cassette transporter, it does not change the internalization of oxLDL. Furthermore, macrophages activated by AITC weakens the inflammatory response induced by tumor necrosis factor- $\alpha$, hence a recent study also reached a similar conclusion, TRPA1-/-ApoE-/mice atherosclerotic plaque increased significantly (Wang Q. et al., 2020). The activation of TRPA1 by cinnamaldehyde significantly slows the progression of atherosclerosis. The researchers found out that inhibition of TRPA1 significantly stimulated the expression of M1 marker genes. TRPA1, which is upregulated in atherosclerotic plaques, can regulate the inflammatory phenotype of macrophages, thereby regulating the progress of atherosclerosis (Wang Q. et al., 2020). Therefore, TRPA1 plays a crucial role in the mechanism of atherosclerosis formation and it could be a therapeutic target for atherosclerosis and other metabolic diseases.

The current study confirmed that TRPA1 is associated with atherosclerosis, and it plays a key role in the macrophage cholesterol outflow and inflammation. However, it is not clear how the TRPA1 channel depends on the $\mathrm{Ca}^{2+}$ influx to mediate macrophage-derived foam cell formation. Lysophosphatidylcholine (LPC) is the main atherosclerotic lipid that stimulates the increase in mitochondrial reactive oxygen species (mtROS) and releases cytokines upon activation of the inflammatory body. A recent study examined the functional expression of TRPA1 in macrophages derived from the human acute monocytic leukemia cell line (THP-1). LPC induces the activation of THP-1-derived macrophages through $\mathrm{Ca}^{2+}$ influx, and TRPA1 inhibitors inhibit this activation. TRPA1 is involved in regulating $\mathrm{Ca}^{2+}$ influx caused by LPC. This result indicates that TRPA1 has important physiological functions in macrophages and is widely involved in the inflammation caused by LPC (Tian et al., 2020). This may be the early stage of macrophage foam cell. Further studies should be conducted to reveal the specific role of TRPA1 in the formation of macrophage foam cells.

\section{TRPA1 and Myocardial Fibrosis}

Myocardial fibrosis refers to the excessive deposition of collagen fibers in myocardial tissue, the imbalance of various types of collagen, and the disorder of arrangement. Abnormal activation of cardiac fibroblasts is closely related to the formation of myocardial fibrosis. Myocardial fibroblasts are directed to the injury site under the influence of various pathological factors such as pressure overload, endothelial injury, hypoxic-ischemic injury, and generate a large number of extracellular matrix (ECM) mediated by local inflammatory factors, cytokines, and neurohumoral factors (Ma et al., 2012). Changes in the composition of myocardial ECM are the pathological basis of myocardial fibrosis. The process of myocardial fibrosis causes abnormalities in myocardial function, metabolism, and transmission, which leads to heart failure, various arrhythmias, and other heart disorders. Studies have shown that endogenous bioactive substances produced by cardiac fibroblasts regulate their activation. Furthermore, $\mathrm{Ca}^{2+}$-dependent signaling is essential for the proliferation of cardiac fibroblasts. Thus, understanding the effects and regulatory mechanisms of endogenous bioactive substances and $\mathrm{Ca}^{2+}$-dependent signaling on cardiac fibroblasts, which will provide new targets for antifibrosis strategies.

The autocrine of calcitonin gene-related peptide (CGRP) in myocardial fibroblasts may cause a positive cardiovascular effect, which relates to the inhibition of myocardial fibrosis (Russell et al., 2014). TRPA1 has been proven to promote the synthesis and secretion of CGRP and intracellular $\mathrm{Ca}^{2+}$ under the action of non-specific agonist AITC, while TRPA1 specific antagonist HC030031 can reverse these effects. CGRP is abundant in rat, mouse, and human myocardium, and it shows that cardiac CGRP develops from cardiac fibroblasts. In an animal experiment, calcitonin/CGRP knockout (KO) mice showed significant cardiac phenotypes, including cardiac remodeling and myocardial fibrosis (Supowit et al., 2005). The TGF- $\beta$ superfamily is an important multifunctional growth factor that not only mediates cell growth, proliferation, and differentiation but also plays an important role in wound healing and the formation of ECM. It was discovered that TGF- $\beta 1$ induced the activation of cardiac fibroblasts, and found that TGF- $\beta 1$ can increase the mRNA expression of cardiac fibroblasts and the secretion level of CGRP. CGRP8-37 (CGRP receptor antagonist) exacerbates TGF- $\beta 1$-induced cardiac fibroblast proliferation, differentiation, collagen production, and inflammation, thus indicating the decisive role of CGRP secretion in the formation of myocardial fibrosis. CGRP of cardiac fibroblasts is also an endogenous inhibitor of cardiac fibrosis. Furthermore, monocrotaline (MCT) is used to induce pulmonary hypertension, which gradually led to right ventricular fibrosis. The non-toxic TRPA1 agonist cinnamaldehyde (CA) inhibits MCT-induced pulmonary hypertension, which increases the $\mathrm{RVSP}, \mathrm{RV} / \mathrm{LV}+\mathrm{S}$, and right ventricular collagen accumulation, and downregulation of CGRP (Li et al., 2019). This indicates that TRPA1 activation has potential benefits in inhibiting TGF- $\beta 1$ induced myocardial fibrosis.

Methylglyoxal (MG), also known as pyruvaldehyde, can activate TRPA1, which is a toxic by-product of glycolysis. It is distributed in all cells of mammals and is associated with various vascular diseases (Wang et al., 2019). In an in vitro study, myocardial fibroblast differentiation showed that it closely relates to MG-induced $\mathrm{Ca}^{2+}$ influx, and this effect was attenuated with the inhibition of TRPA1 channels, and the study suggests that MG-induced cardiac fibroblasts require TRPA1-mediated $\mathrm{Ca}^{2+}$ dependent signaling pathway (Oguri et al., 2014). In addition, inhibition of TRPA1 activity can significantly improve the degree of cardiac hypertrophy and myocardial fibrosis in mice, which may be related to weight loss and increase in aortic cross-sectional area (Wang et al., 2018).

Autocrine CGRP and $\mathrm{Ca}^{2+}$-dependent signaling of cardiac fibroblasts play an important role in the process of myocardial fibrosis formation. TRPA1 promotes the secretion of CGRP under the action of agonists and then inhibit the formation of myocardial fibrosis. However, TRPA1 inhibition antagonizes MG-induced $\mathrm{Ca}^{2+}$ influx. Subsequently, TRPA1 has opposite roles in the two pathways. At least it is clear that TRPA1 plays an important role in the pathological process of myocardial fibrosis. Further research should be done to consider the role of TRPA1 
in different stages of myocardial fibrosis formation and use this potential therapeutic target more accurately.

\section{TRPA1 and Heart Failure}

Heart failure is the ultimate destination of most cardiovascular diseases, which leads to heart circulation disorder caused by systolic or diastolic dysfunction. The activation of various neuroendocrine mechanisms such as the renin-angiotensin system, pro-inflammatory factors, and natriuretic peptide system closely relates to the development of heart failure (Geng et al., 2019; Hsu et al., 2020). Abnormal activation of the sympathetic nervous system is one of the most critical pathophysiological characteristics of heart failure (Sousa-Pinto et al., 2014). Excessive cardiac sympathetic reflex helps in nerve excitement. In an animal model experiment, capsaicin, as an agonist of TRPV1, enhanced cardiac sympathetic reflex. Capsaicin given after cutting off the vagus nerve in a rat heart failure model increased mean arterial pressure, heart rate, and renal sympathetic nerve activity (Adam et al., 2019). This suggests that TRPV1 activation enhances the degree of heart failure. Because of the similarity of TRPV1 and TRPA1 channels, TRPA1 activation may mediate cardiac sympathetic excitation. In addition, $\mathrm{Ca}^{2+}$ plays an important role in the myocardial excitation-contraction coupling mechanism, and myocardial cells in heart failure models show abnormal Ca ${ }^{2+}$ flow (Bers, 2006; Roe et al., 2015). The exact mechanism is unclear, however, as to the causes of abnormal sympathetic nerve excitement and heart muscle cell $\mathrm{Ca}^{2+}$ insufficiency. In the future, research must focus on these important targets for reducing heart failure.

The TRPA1 channel-mediated sympathetic reflex is unclear. It is worth noting that excessive sympathetic nerve excitation is a characteristic of chronic heart failure (CHF). In a recent study, the use of TRPA1 agonists to the surface of the heart and lungs increased heart rate and sympathetic nerve output in the control group of rats, on average arterial pressure, which changes in two phases. However, these effects are attenuated in CHF rats, thereby reducing the possibility of TRPA1 channel sensitization to CHF cardiopulmonary afferent (Adam et al., 2019). This shows that activation of the TRPA1 channel does not mediate an increase in sympathetic nerve reflexes and slightly decreases in CHF rats. In a mouse model experiment, the AITC stimulation of TRPA1 caused a dose-dependent increase in the peak $\left[\mathrm{Ca}^{2+}\right]_{I}$ of isolated cardiomyocytes, time, and speed of reaching the peak of $\left[\mathrm{Ca}^{2+}\right]_{\mathrm{I}}$. However, no change in $\left[\mathrm{Ca}^{2+}\right]_{\mathrm{I}}$ was observed in cardiomyocytes pretreated with TRPA1 antagonist HC-030031 or cardiomyocytes obtained from TRPA1-/- mice (Andrei et al., 2017). TRPA1 stimulation leads to rapid phosphorylation of $\mathrm{Ca}^{2+} /$ calmodulindependent kinase II (CaMKII). The stimulation of TRPA1 ion channels in cardiomyocytes mediates the activation of CaMKIIdependent signaling pathways, which increases cardiomyocytes contractile function (Marks, 2013; Roe et al., 2015). This may suggest that TRPA1 is involved in the regulation of heart failure through a $\mathrm{Ca}^{2+}$-dependent mechanism.

To our knowledge from previous studies, it seems that there is no direct evidence that TRPA1 activation causes sympathetic nerve excitation and that mediates heart failure. The current research results indicate that activation of the TRPA1 channel does not cause an increase in sympathetic reflex under heart failure. However, other studies suggest that the activation of TRPA1 channel helps to enhance cardiomyocyte contractility.

\section{TRPA1 and Arrhythmia}

Arrhythmia is caused by the abnormal sinus node activation or excitement which occurs outside the sinus node, resulting in abnormal heartbeat frequency or rhythm. It is an important group of cardiovascular diseases, which includes premature atrial complexes, premature ventricular complexes, atrial fibrillation, and ventricular tachycardia (Goudis et al., 2015). Genetic factors and other external factors can cause arrhythmia. Numerous studies have shown that there is a potential connection between air pollution and arrhythmia (Watkins et al., 2013; Monrad et al., 2017). In addition, the heart rhythm regulated by the autonomic nervous system (ANS) and air pollution increase the possibility of arrhythmia by interfering with the ANS balance (Wu et al., 2015).

ANS plays an important role in regulating arrhythmia. Some studies suggest that $\mathrm{PM}_{2.5}$ interferes with the balance of ANS, thus resulting in increased heart rate, reduced heart rate variability, and increased risk of arrhythmia (Watkins et al., 2013; Shen and Zipes, 2014; Feng et al., 2019). In another study, exposure to automobile exhaust increased sympathetic excitability in hypertensive rats, and this sensitivity decreased with the application of TRPA1 inhibitors (Hazari et al., 2011). On the other hand, AITC increased the incidence of arrhythmia in rats, and this effect is inhibited by cholinergic antagonists (Hooper et al., 2016). Furthermore, acrolein, a smoke component, increases the heart rate variability and arrhythmia in mice, and this effect disappears after knocking out the TRPA1 gene or giving TRPA1 inhibitors (Kurhanewicz et al., 2017, 2018; Thompson et al., 2019). Continued exposure to air pollution, toxic chemicals, and particulate matter (PM) causes inflammation of the lungs, leading to cough, asthma, chronic obstructive pulmonary disease (COPD), and other diseases. Studies have indicated that PM activates TRPA1 activity in the respiratory tract, which induces human lung disease (DeeringRice et al., 2011; Akopian et al., 2016). As the level of systemic inflammation increases, the risk of atrial fibrillation in COPD subjects increases (Grymonprez et al., 2019), and there is a negative relationship between the level of asthma control and the increased risk of atrial fibrillation (Cepelis et al., 2018). This seems to suggest that TRPA1 activation indirectly causes arrhythmia. These findings indicate that the TRPA1 channel may stimulate arrhythmia through an airway inflammation and ANS imbalance.

The ANS can be divided into the sympathetic nervous system and the parasympathetic nervous system. The autonomic nervous system mainly innervates the muscles and smooth muscles of the internal organs, glands, and blood vessel walls. Pain, fear, and temperature can cause stress regulation of ANS. Owing to different types of harmful components in air pollution, the effect of TRPA 1 activation is not absolute, however, activation of the sympathetic nervous system or parasympathetic nervous system is different (Middlekauff et al., 2014; Perez et al., 2015), thus, the role of the TRPA 1 channel on cardiac autonomic nerves needs further investigation. Furthermore, previous reports stated 
that the activation of TRPA1 mediates the production of airway inflammation, causing lung inflammation, which increases the risk of arrhythmia to some extent. The activation of TRPA1 indirectly promotes the occurrence of arrhythmia.

\section{Relationship Between TRPA1 and Other Cardiovascular Disease Risk Factors}

In addition to the primary physiological and pathological changes of the cardiovascular system, the occurrence and development of cardiovascular diseases are often secondary to other risk factors. There are many risk factors for cardiovascular disease, including diabetes, hypertension, dyslipidemia, age, genetics, and lifestyle habits (Park et al., 2020; Ungar et al., 2020). TRPA1 closely relates to many risk factors of cardiovascular disease.

\section{TRPA1 and Glycolipid Metabolism}

Glycolipid metabolism disorder is a key factor in the formation of cardiovascular disease (Delitala et al., 2017). Metabolic diseases such as obesity and diabetes are important conditions for causing the development of cardiovascular diseases (Jokinen, 2015; Hansen, 2018). Diabetes manifests as insulin resistance and impaired insulin signaling. Hyperinsulinemia and hyperglycemia together accelerate the development of atherosclerosis (Bornfeldt and Tabas, 2011; Tabas, 2017). In particular, acute hyperglycemia weakens endothelial function and reduces the bioavailability of nitric oxide (Williams et al., 1998), increasing leukocyte adhesion (Perkins et al., 2015). In the state of hyperglycemia, the phenotype of vascular smooth muscle cells changes from a static, contracted state to an activated, proliferative state, which accelerates the progress of atherosclerosis (Zheng et al., 2007).

Atherosclerosis is the basis of other cardiovascular diseases; hence, many cardiovascular diseases develop from atherosclerosis (Frostegard, 2013). TRPA1 plays an important role in regulating glycolipid metabolism, which has important significance for the treatment of atherosclerosis (Zhao et al., 2016). Islet function, insulin level, and sensitivity are important factors that affect glucose metabolism. Studies have found that TRPA1 is abundant in rat islet $\beta$ cells. AITC, $\mathrm{H}_{2} \mathrm{O}_{2}$, and $15 \mathrm{~d}-\mathrm{PGJ} 2$ activate TRPA1 in islet $\beta$ cells and stimulate insulin secretion (Cao et al., 2012; Numazawa et al., 2012). Ghrelin, GLP-1, and other intestinal hormones affect the metabolism of glycolipids through various mechanisms. TRPA1 was present in endocrine cells in the mouse small intestine, and activating TRPA1 on these cells promoted GLP-1 secretion in a calcium-dependent manner (Shrestha et al., 2018). Cinnamaldehyde significantly inhibits the secretion of ghrelin by activating TRPA1 in the intestine to reduce food intake, and has the effect of weight loss and blood sugar reduction (Emery et al., 2015).

Cinnamaldehyde is a specific agonist of TRPA1 and has a moderate hypoglycemic effect on patients with type 2 diabetes (Rafehi et al., 2012). It has been confirmed that cinnamaldehyde promotes insulin and GLP-1 secretion (Numazawa et al., 2012; Shrestha et al., 2018), improves insulin sensitivity, and reduces liver fat deposition (Sartorius et al., 2014). The activation of pancreatic $\beta$-cell TRPA1 also promotes insulin secretion (Cao et al., 2012), as well as mesenteric adipose tissue which suggests that TRPA1 has a regulatory role in glucose metabolism. Intake of cinnamaldehyde has been shown to reduce visceral adipose tissue in high-fat and high-sugar fed mice (Tamura et al., 2012). This suggests that TRPA1 also has a potential regulatory role in lipid metabolism. In conclusion, the activation of TRPA1 indirectly reduces the incidence of cardiovascular diseases caused by glucose and lipid metabolism disorders.

\section{TRPA1 and Oxidative Stress}

Oxidative stress refers to the tissue damage caused by the excessive production of highly reactive molecular oxygen species (ROS) and reactive nitrogen species (RNS) or the inability to eliminate them in the body (Del Rio, 2015). Although the organism has established a relatively complete anti-oxidative stress system during evolution, the balance between oxidation and anti-oxidation will eventually be broken under the joint action of various risk factors. The products of oxidative stress lead to cardiovascular metabolic diseases (Sverdlov et al., 2016; Faria and Persaud, 2017; van der Pol et al., 2019). ROS, RNS, 4-hydroxynon-enal (4-HNE), $\mathrm{H}_{2} \mathrm{O}_{2}, \mathrm{NO}, \mathrm{H}_{2} \mathrm{~S}$, prostaglandin J2 (15d-PGJ2) are all TRPA1 direct or indirect agonists (Hinman et al., 2006; Taylor-Clark et al., 2009). This shows that oxidative stress metabolites can activate TRPA1, which is considered to be the endogenous substance that regulates TRPA1 in the body (Cao et al., 2012; Tamura et al., 2012). However, the relevant pathophysiological significance is currently unknown.

Previous studies confirmed that several TRPA1 agonists such as cinnamic aldehyde, artemisinol, and mustard oil have significant antioxidant activity, which activates the classic Nrf2/ARE antioxidant stress pathway (Huang et al., 2011; Zheng et al., 2011; Hsu et al., 2013). TRPA1 agonist cinnamaldehyde significantly antagonizes high glucose-mediated vascular endothelial oxidative stress through the Nrf2 pathway (Wang et al., 2015; Takahashi et al., 2018). Therefore, the role of TRPA1 and its agonists in the process of oxidative stress is worthy of further research. Among all subgroups of the TRP family, TRPA1 is the most sensitive to ROS. Its activation depends on the modification of the cysteine residue at the $\mathrm{N}$-terminal end of the protein. Oxidation and peroxidation of cysteine residues cause residues to bind to disulfide bonds, which enhances TRPA1 activity (MacPherson et al., 2007a). TRPA1 is present in cardiomyocytes and is important in regulating myocardial reperfusion injury (Lu et al., 2016). A study showed that TRPA1 gene-knockout myocardial ischemia-reperfusion mice alleviated myocardial injury, indicating that TRPA1 channel activation mediates myocardial ischemia-reperfusion injury (Conklin et al., 2019). This may be related to the accumulation of free radicals and unsaturated aldehydes generated after myocardial ischemia and reperfusion to activate TRPA1 channel. The activated TRPA1 channel mediates a large amount of $\mathrm{Ca}^{2+}$ influx, aggravating inflammation and ischemia-reperfusion injury. Therefore, TRPA1 could be a potential drug target for reducing myocardial ischemia-reperfusion injury. In conclusion, the mechanism in which oxidative stress products activate TRPA1-mediated cardiovascular disease needs to be further discussed. 


\section{TRPA1 and Aging}

With aging, the damage of molecules, cells, and tissues in the body leads to an imbalanced state, which makes the body's functions degenerate or cause diseases (Wu et al., 2019b). As a nutrient delivery channel of the human body, blood vessels play an important role in maintaining normal physiological functions. After entering old age, vascular aging becomes an independent risk factor for cardiovascular diseases (Costantino et al., 2016; He, 2016).

Current research reflects that mammalian lifespan is closely related to mitochondrial aging, oxidative stress, diet, insulin/IGF1 signaling pathway, and UCP2 (Katic and Kahn, 2005; Duangjan et al., 2019), but the exact mechanism is still unclear. DAF-16 gene is a kind of lifespan regulator, called forkhead transcription factors of the $\mathrm{O}$ class (FOXO) in mammals (Jahn et al., 2020). Other studies revealed that hypothermiaactivated TRPA1 regulates the downstream DAF-16/FOXO pathway through calcium-sensitive protein kinase C2 (PKC-2) signaling to extend lifespan (Xiao et al., 2013). However, lowtemperature activation of TRPA1 failed to extend the lifespan of young individuals, which suggests that activation of TRPA1 plays a more important role in extending lifespan in adult and elderly individuals (Zhang et al., 2015). This is relatively related to the stable redox system in young individuals. These studies confirmed that low-temperature activation of TRPA1 could prolong the lifespan, but the specific mechanism still needs further clarification.

Aging is closely related to vascular aging; therefore, activating TRPA1 can significantly prolong life. Moreover, current research denotes that TRPA1 may have proper metabolic regulation and cardiovascular protection. Therefore, the role and mechanism of TRPA1 on age-related vascular damage should be explored further in combination with in vitro vascular culture and vascular endothelial-specific knockout mice.

\section{REFERENCES}

Adam, R. J., Xia, Z., Pravoverov, K., Hong, J., and Case, A. J. (2019). Sympathoexcitation in response to cardiac and pulmonary afferent stimulation of TRPA1 channels is attenuated in rats with chronic heart failure. Am. J. Physiol. Heart Circ. Physiol. 316, H862-H872.

Akopian, A. N., Fanick, E. R., and Brooks, E. G. (2016). TRP channels and traffic-related environmental pollution-induced pulmonary disease. Semin. Immunopathol. 38, 331-338. doi: 10.1007/s00281-016-0554-4

Alali, F. Q., El-Elimat, T., Khalid, L., Hudaib, R., Al-Shehabi, T. S., and Eid, A. H. (2017). Garlic for cardiovascular disease: prevention or treatment? Curr. Pharm. Des. 23, 1028-1041. doi: 10.2174/1381612822666161010124530

Alpizar, Y. A., Gees, M., Sanchez, A., Apetrei, A., Voets, T., Nilius, B., et al. (2013). Bimodal effects of cinnamaldehyde and camphor on mouse TRPA1. Pflugers Arch. 465, 853-864. doi: 10.1007/s00424-012-1204-x

Andersson, D. A., Gentry, C., Moss, S., and Bevan, S. (2008). Transient receptor potential A1 is a sensory receptor for multiple products of oxidative stress. J. Neurosci. 28, 2485-2494. doi: 10.1523/jneurosci.5369-07.2008

Andre, E., Campi, B., Materazzi, S., Trevisani, M., Amadesi, S., Massi, D., et al. (2008). Cigarette smoke-induced neurogenic inflammation is mediated by alpha,beta-unsaturated aldehydes and the TRPA1 receptor in rodents. J. Clin. Invest. 118, 2574-2582.

Andrei, S. R., Ghosh, M., Sinharoy, P., Dey, S., Bratz, I. N., and Damron, D. S. (2017). TRPA1 ion channel stimulation enhances cardiomyocyte contractile

\section{CONCLUSION}

TRPA1's role in cardiovascular diseases has received extensive attention, and it is directly or indirectly involved in the occurrence and development of cardiovascular diseases. This review describes the role of TRPA1 channels in common cardiovascular diseases. The TRPA1 channel is involved in mediating vascular physiological functions, which closely relates to the regulation of vasodilation and blood pressure. However, this regulation of blood pressure is biphasic. The activation of TRPA1 channel has a protective effect on the development of atherosclerosis; its channel blockade is beneficial for arrhythmia progression. The role of TRPA1 in the formation of heart failure and myocardial fibrosis is difficult to determine, and further experimental proof is needed. This review found evidence that TRPA1 channels relate closely to glucose and lipid metabolism, oxidative stress, and vascular aging. Considering the relationship between TRPA1 channel and various cardiovascular diseases, it may be a potential target for clinical treatment of cardiovascular diseases. In addition, according to the new drug design stage, the dual function of the TRPA1 channel should be fully considered.

\section{AUTHOR CONTRIBUTIONS}

SG and KK conceived the review and drafted the manuscript. SG and $S Z$ revised the manuscript critically for important intellectual content. TL, PC, and RW provided funding for research. All authors approved the final version of the manuscript submitted.

\section{FUNDING}

This study was supported by the National Key R\&D Program of China (No. 2018YFC1314701).

function via a CaMKII-dependent pathway. Channels 11, 587-603. doi: 10. 1080/19336950.2017.1365206

Aubdool, A. A., Graepel, R., Kodji, X., Alawi, K. M., Bodkin, J. V., Srivastava, S., et al. (2014). TRPA1 is essential for the vascular response to environmental cold exposure. Nat. Commun. 5:5732.

Aubdool, A. A., Kodji, X., Abdul-Kader, N., Heads, R., Fernandes, E. S., Bevan, S., et al. (2016). TRPAl activation leads to neurogenic vasodilatation: involvement of reactive oxygen nitrogen species in addition to CGRP and NO. Br. J. Pharmacol. 173, 2419-2433. doi: 10.1111/bph.13519

Bandell, M., Story, G. M., Hwang, S. W., Viswanath, V., Eid, S. R., Petrus, M. J., et al. (2004). Noxious cold ion channel TRPAl is activated by pungent compounds and bradykinin. Neuron 41, 849-857. doi: 10.1016/s0896-6273(04)00150-3

Bautista, D. M., Jordt, S. E., Nikai, T., Tsuruda, P. R., Read, A. J., Poblete, J., et al. (2006). TRPA1 mediates the inflammatory actions of environmental irritants and proalgesic agents. Cell 124, 1269-1282. doi: 10.1016/j.cell.2006.02.023

Bautista, D. M., Movahed, P., Hinman, A., Axelsson, H. E., Sterner, O., Hogestatt, E. D., et al. (2005). Pungent products from garlic activate the sensory ion channel TRPA1. Proc. Natl. Acad. Sci. U.S.A. 102, 12248-12252. doi: 10.1073/ pnas.0505356102

Benemei, S., De Cesaris, F., Fusi, C., Rossi, E., Lupi, C., and Geppetti, P. (2013). TRPA1 and other TRP channels in migraine. J. Headache Pain 14, 71.

Benemei, S., Fusi, C., Trevisan, G., and Geppetti, P. (2014). The TRPAl channel in migraine mechanism and treatment. Br. J. Pharmacol. 171, 2552-2567. doi: 10.1111/bph.12512 
Bers, D. M. (2006). Altered cardiac myocyte Ca regulation in heart failure. Physiology 21, 380-387. doi: 10.1152/physiol.00019.2006

Bodkin, J. V., and Brain, S. D. (2011). Transient receptor potential ankyrin 1: emerging pharmacology and indications for cardiovascular biology. Acta Physiol. 203, 87-98. doi: 10.1111/j.1748-1716.2010.02203.x

Bonet, I. J., Fischer, L., Parada, C. A., and Tambeli, C. H. (2013). The role of transient receptor potential A 1 (TRPA1) in the development and maintenance of carrageenan-induced hyperalgesia. Neuropharmacology 65, 206-212. doi: 10. 1016/j.neuropharm.2012.09.020

Bornfeldt, K. E., and Tabas, I. (2011). Insulin resistance, hyperglycemia, and atherosclerosis. Cell Metab. 14, 575-585. doi: 10.1016/j.cmet.2011.07.015

Brunt, V. E., Fujii, N., and Minson, C. T. (2013). No independent, but an interactive, role of calcium-activated potassium channels in human cutaneous active vasodilation. J. Appl. Physiol. 115, 1290-1296. doi: 10.1152/japplphysiol. 00358.2013

Cao, D. S., Zhong, L., Hsieh, T. H., Abooj, M., Bishnoi, M., Hughes, L., et al. (2012). Expression of transient receptor potential ankyrin 1 (TRPA1) and its role in insulin release from rat pancreatic beta cells. PLoS One 7:e38005. doi: 10.1371/journal.pone.0038005

Cepelis, A., Brumpton, B. M., Malmo, V., Laugsand, L. E., Loennechen, J. P., Ellekjaer, H., et al. (2018). Associations of asthma and asthma control with atrial fibrillation risk: results from the nord-trondelag health study (HUNT). JAMA Cardiol. 3, 721-728.

Chen, J., Joshi, S. K., Didomenico, S., Perner, R. J., Mikusa, J. P., Gauvin, D. M., et al. (2011). Selective blockade of TRPA1 channel attenuates pathological pain without altering noxious cold sensation or body temperature regulation. Pain 152, 1165-1172. doi: 10.1016/j.pain.2011.01.049

Chen, J., Kang, D., Xu, J., Lake, M., Hogan, J. O., Sun, C., et al. (2013). Species differences and molecular determinant of TRPA1 cold sensitivity. Nat. Commun. 4:2501.

Conklin, D. J., Guo, Y., Nystoriak, M. A., Jagatheesan, G., Obal, D., Kilfoil, P. J., et al. (2019). TRPAl channel contributes to myocardial ischemia-reperfusion injury. Am. J. Physiol. Heart Circ. Physiol. 316, H889-H899.

Cosens, D. J., and Manning, A. (1969). Abnormal electroretinogram from a Drosophila mutant. Nature 224, 285-287. doi: 10.1038/224285a0

Costantino, S., Paneni, F., and Cosentino, F. (2016). Ageing, metabolism and cardiovascular disease. J. Physiol. 594, 2061-2073. doi: 10.1113/jp270538

Deering-Rice, C. E., Romero, E. G., Shapiro, D., Hughen, R. W., Light, A. R., Yost, G. S., et al. (2011). Electrophilic components of diesel exhaust particles (DEP) activate transient receptor potential ankyrin-1 (TRPA1): a probable mechanism of acute pulmonary toxicity for DEP. Chem. Res. Toxicol. 24, 950-959. doi: $10.1021 / \mathrm{tx} 200123 \mathrm{z}$

Defalco, J., Steiger, D., Gustafson, A., Emerling, D. E., Kelly, M. G., and Duncton, M. A. (2010). Oxime derivatives related to AP18: agonists and antagonists of the TRPA1 receptor. Bioorg. Med. Chem. Lett. 20, 276-279. doi: 10.1016/j.bmcl. 2009.10.113

Del Rio, L. A. (2015). ROS and RNS in plant physiology: an overview. J. Exp. Bot. 66, 2827-2837. doi: 10.1093/jxb/erv099

Delitala, A. P., Fanciulli, G., Maioli, M., and Delitala, G. (2017). Subclinical hypothyroidism, lipid metabolism and cardiovascular disease. Eur. J. Intern. Med. 38, 17-24. doi: 10.1016/j.ejim.2016.12.015

Derbenev, A. V., and Zsombok, A. (2016). Potential therapeutic value of TRPV1 and TRPA1 in diabetes mellitus and obesity. Semin. Immunopathol. 38, 397406. doi: 10.1007/s00281-015-0529-x

Dietrich, A., Steinritz, D., and Gudermann, T. (2017). Transient receptor potential (TRP) channels as molecular targets in lung toxicology and associated diseases. Cell Calcium 67, 123-137. doi: 10.1016/j.ceca.2017.04.005

Duangjan, C., Rangsinth, P., Gu, X., and Wink, M. (2019). Lifespan extending and oxidative stress resistance properties of a leaf extracts from Anacardium occidentale L. in Caenorhabditis elegans. Oxid. Med. Cell. 2019:9012396.

Earley, S. (2012). TRPA1 channels in the vasculature. Br. J. Pharmacol. 167, 13-22. doi: $10.1111 / j .1476-5381.2012 .02018 . x$

Earley, S., Gonzales, A. L., and Crnich, R. (2009). Endothelium-dependent cerebral artery dilation mediated by TRPA1 and Ca2+-Activated $\mathrm{K}+$ channels. Circ. Res. 104, 987-994. doi: 10.1161/circresaha.108.189530

Earley, S., Gonzales, A. L., and Garcia, Z. I. (2010). A dietary agonist of transient receptor potential cation channel V3 elicits endothelium-dependent vasodilation. Mol. Pharmacol. 77, 612-620. doi: 10.1124/mol.109.060715
Eberhardt, M., Dux, M., Namer, B., Miljkovic, J., Cordasic, N., Will, C., et al. (2014). H2S and NO cooperatively regulate vascular tone by activating a neuroendocrine HNO-TRPA1-CGRP signalling pathway. Nat. Commun. 5:4381.

Emery, E. C., Diakogiannaki, E., Gentry, C., Psichas, A., Habib, A. M., Bevan, S., et al. (2015). Stimulation of GLP-1 secretion downstream of the ligand-gated ion channel TRPA1. Diabetes 64, 1202-1210. doi: 10.2337/db14-0737

Faria, A., and Persaud, S. J. (2017). Cardiac oxidative stress in diabetes: mechanisms and therapeutic potential. Pharmacol. Ther. 172, 50-62. doi: 10. 1016/j.pharmthera.2016.11.013

Feng, B., Song, X., Dan, M., Yu, J., Wang, Q., Shu, M., et al. (2019). High level of source-specific particulate matter air pollution associated with cardiac arrhythmias. Sci. Total Environ. 657, 1285-1293. doi: 10.1016/j.scitotenv.2018. 12.178

Frostegard, J. (2013). Immunity, atherosclerosis and cardiovascular disease. BMC Med. 11:117. doi: 10.1186/1741-7015-11-117

Geng, Q., Li, S., Wang, Z., and Ren, Y. (2019). Efficacy and safety of combined neprilysin and RAS inhibition in heart failure: a meta-analysis of randomized controlled trials. Int. J. Cardiol. 293, 159-164. doi: 10.1016/j.ijcard.2019.05.048

Goudis, C. A., Konstantinidis, A. K., Ntalas, I. V., and Korantzopoulos, P. (2015). Electrocardiographic abnormalities and cardiac arrhythmias in chronic obstructive pulmonary disease. Int. J. Cardiol. 199, 264-273. doi: 10.1016/j. ijcard.2015.06.096

Graepel, R., Fernandes, E. S., Aubdool, A. A., Andersson, D. A., Bevan, S., and Brain, S. D. (2011). 4-oxo-2-nonenal (4-ONE): evidence of transient receptor potential ankyrin 1-dependent and -independent nociceptive and vasoactive responses in vivo. J. Pharmacol. Exp. Ther. 337, 117-124. doi: 10.1124/jpet.110. 172403

Grymonprez, M., Vakaet, V., Kavousi, M., Stricker, B. H., Ikram, M. A., Heeringa, J., et al. (2019). Chronic obstructive pulmonary disease and the development of atrial fibrillation. Int. J. Cardiol. 276, 118-124.

Guo, S., Huang, Y., Zhang, Y., Huang, H., Hong, S., and Liu, T. (2020). Impacts of exercise interventions on different diseases and organ functions in mice. J. Sport Health Sci. 9, 53-73. doi: 10.1016/j.jshs.2019.07.004

Hamlin, R. L. (2007). Animal models of ventricular arrhythmias. Pharmacol. Ther. 113, 276-295. doi: 10.1016/j.pharmthera.2006.08.006

Hansen, P. R. (2018). Chronic inflammatory diseases and atherosclerotic cardiovascular disease: innocent bystanders or partners in crime? Curr. Pharm. Des. 24, 281-290.

Hardie, R. C., and Minke, B. (1992). The trp gene is essential for a light-activated Ca2+ channel in Drosophila photoreceptors. Neuron 8, 643-651. doi: 10.1016/ 0896-6273(92)90086-s

Hazari, M. S., Haykal-Coates, N., Winsett, D. W., Krantz, Q. T., King, C., Costa, D. L., et al. (2011). TRPA1 and sympathetic activation contribute to increased risk of triggered cardiac arrhythmias in hypertensive rats exposed to diesel exhaust. Environ. Health Perspect. 119, 951-957. doi: 10.1289/ehp.1003200

He, J. (2016). Hypertension in China: a large and increasing public health challenge. J. Hypertens 34, 29-31. doi: 10.1097/hjh.0000000000000818

Hinman, A., Chuang, H. H., Bautista, D. M., and Julius, D. (2006). TRP channel activation by reversible covalent modification. Proc. Natl. Acad. Sci.U.S.A. 103, 19564-19568. doi: 10.1073/pnas.0609598103

Hofmann, L., Wang, H., Zheng, W., Philipp, S. E., Hidalgo, P., Cavalie, A., et al. (2017). The S4-S5 linker - gearbox of TRP channel gating. Cell Calcium 67, 156-165. doi: 10.1016/j.ceca.2017.04.002

Hooper, J. S., Hadley, S. H., Morris, K. F., Breslin, J. W., Dean, J. B., and TaylorClark, T. E. (2016). Characterization of cardiovascular reflexes evoked by airway stimulation with allylisothiocyanate, capsaicin, and ATP in Sprague-Dawley rats. J. Appl. Physiol. 120, 580-591. doi: 10.1152/japplphysiol.00944.2015

Hsu, C. C., Fu, T. C., Huang, S. C., and Wang, J. S. (2020). High-intensity interval training recuperates capacity of endogenous thrombin generation in heart failure patients with reduced ejection fraction. Thromb. Res. 187, 159-165. doi: 10.1016/j.thromres.2020.01.013

Hsu, W. H., Lee, B. H., Li, C. H., Hsu, Y. W., and Pan, T. M. (2013). Monascin and AITC attenuate methylglyoxal-induced PPARgamma phosphorylation and degradation through inhibition of the oxidative stress/PKC pathway depending on Nrf2 activation. J. Agric. Food Chem. 61, 5996-6006. doi: 10.1021/jf401197r

Huang, T. C., Chung, Y. L., Wu, M. L., and Chuang, S. M. (2011). Cinnamaldehyde enhances Nrf2 nuclear translocation to upregulate phase II detoxifying enzyme 
expression in HepG2 cells. J. Agric. Food Chem. 59, 5164-5171. doi: 10.1021/ jf $200579 \mathrm{~h}$

Huddy, K., Dhesi, P., and Thompson, P. D. (2013). Do the frequencies of adverse events increase, decrease, or stay the same with long-term use of statins? Curr. Atheroscler. Rep. 15:301.

Inoue, R., Jian, Z., and Kawarabayashi, Y. (2009). Mechanosensitive TRP channels in cardiovascular pathophysiology. Pharmacol. Ther. 123, 371-385. doi: 10. 1016/j.pharmthera.2009.05.009

Ivanov, S., and Lagunin, A. (2019). Assessment of the cardiovascular adverse effects of drug-drug interactions through a combined analysis of spontaneous reports and predicted drug-target interactions. PLoS Comput. Biol. 15:e1006851. doi: 10.1371/journal.pcbi.1006851

Jahn, A., Scherer, B., Fritz, G., and Honnen, S. (2020). Statins Induce a DAF16/Foxo-dependent Longevity Phenotype via JNK-1 through Mevalonate Depletion in C. elegans. Aging Dis. 11, 60-72.

Jin, L., Jagatheesan, G., Guo, L., Nystoriak, M., Malovichko, M., Lorkiewicz, P., et al. (2019). Formaldehyde induces mesenteric artery relaxation via a sensitive transient receptor potential ankyrin-1 (TRPA1) and endothelium-dependent mechanism: potential role in postprandial hyperemia. Front. Physiol. 10:277. doi: $10.3389 /$ fphys.2019.00277

Jokinen, E. (2015). Obesity and cardiovascular disease. Minerva Pediatr. 67, 25-32.

Jordt, S. E., Bautista, D. M., Chuang, H. H., Mckemy, D. D., Zygmunt, P. M., Hogestatt, E. D., et al. (2004). Mustard oils and cannabinoids excite sensory nerve fibres through the TRP channel ANKTM1. Nature 427, 260-265. doi: 10.1038 /nature 02282

Karashima, Y., Damann, N., Prenen, J., Talavera, K., Segal, A., Voets, T., et al. (2007). Bimodal action of menthol on the transient receptor potential channel TRPA1. J. Neurosci. 27, 9874-9884. doi: 10.1523/jneurosci.2221-07. 2007

Katic, M., and Kahn, C. R. (2005). The role of insulin and IGF-1 signaling in longevity. Cell Mol. Life Sci. 62, 320-343. doi: 10.1007/s00018-004-4297-y

Katz, B., Oberacker, T., Richter, D., Tzadok, H., Peters, M., Minke, B., et al. (2013). Drosophila TRP and TRPL are assembled as homomultimeric channels in vivo. J. Cell Sci. 126, 3121-3133. doi: 10.1242/jcs.123505

Kohler, R., and Ruth, P. (2010). Endothelial dysfunction and blood pressure alterations in K+-channel transgenic mice. Pflugers Arch. 459, 969-976. doi: 10.1007/s00424-010-0819-z

Kojima, R., Nozawa, K., Doihara, H., Keto, Y., Kaku, H., Yokoyama, T., et al. (2014). Effects of novel TRPA1 receptor agonist ASP7663 in models of druginduced constipation and visceral pain. Eur. J. Pharmacol. 723, 288-293. doi: 10.1016/j.ejphar.2013.11.020

Kokel, D., Cheung, C. Y., Mills, R., Coutinho-Budd, J., Huang, L., Setola, V., et al. (2013). Photochemical activation of TRPA1 channels in neurons and animals. Nat. Chem. Biol. 9, 257-263. doi: 10.1038/nchembio.1183

Kovacevic, I., Muller, M., Kojonazarov, B., Ehrke, A., Randriamboavonjy, V., Kohlstedt, K., et al. (2015). The F-BAR protein NOSTRIN dictates the localization of the muscarinic $\mathrm{m} 3$ receptor and regulates cardiovascular function. Circ. Res. 117, 460-469. doi: 10.1161/circresaha.115.306187

Kumar, A., Kumari, S., Majhi, R. K., Swain, N., Yadav, M., and Goswami, C. (2015). Regulation of TRP channels by steroids: implications in physiology and diseases. Gen. Comp. Endocrinol. 220, 23-32. doi: 10.1016/j.ygcen.2014. 10.004

Kun, J., Szitter, I., Kemeny, A., Perkecz, A., Kereskai, L., Pohoczky, K., et al. (2014). Upregulation of the transient receptor potential ankyrin 1 ion channel in the inflamed human and mouse colon and its protective roles. PLoS One 9:e108164. doi: 10.1371/journal.pone.0108164

Kunkler, P. E., Ballard, C. J., Oxford, G. S., and Hurley, J. H. (2011). TRPA1 receptors mediate environmental irritant-induced meningeal vasodilatation. Pain 152, 38-44. doi: 10.1016/j.pain.2010.08.021

Kurganov, E., Zhou, Y., Saito, S., and Tominaga, M. (2014). Heat and AITC activate green anole TRPA1 in a membrane-delimited manner. Pflugers Arch. 466, 1873-1884. doi: 10.1007/s00424-013-1420-z

Kurhanewicz, N., Ledbetter, A., Farraj, A., and Hazari, M. (2018). TRPA1 mediates the cardiac effects of acrolein through parasympathetic dominance but also sympathetic modulation in mice. Toxicol. Appl. Pharmacol. 347, 104-114. doi: 10.1016/j.taap.2018.03.027

Kurhanewicz, N., Mcintosh-Kastrinsky, R., Tong, H., Ledbetter, A., Walsh, L., Farraj, A., et al. (2017). TRPA1 mediates changes in heart rate variability and cardiac mechanical function in mice exposed to acrolein. Toxicol. Appl. Pharmacol. 324, 51-60. doi: 10.1016/j.taap.2016.10.008

Li, W., Zhang, Z., Li, X., Cai, J., Li, D., Du, J., et al. (2019). CGRP derived from cardiac fibroblasts is an endogenous suppressor of cardiac fibrosis. Cardiovasc. Res. 116, 1335-1348. doi: 10.1093/cvr/cvz234

Lin, Y. W., Liu, P. S., Adhikari, N., Hall, J. L., and Wei, L. N. (2015). RIP140 contributes to foam cell formation and atherosclerosis by regulating cholesterol homeostasis in macrophages. J. Mol. Cell Cardiol. 79, 287-294. doi: 10.1016/j. yjmcc.2014.12.009

Lu, Y., Piplani, H., Mcallister, S. L., Hurt, C. M., and Gross, E. R. (2016). Transient receptor potential ankyrin 1 activation within the cardiac myocyte limits ischemia-reperfusion injury in rodents. Anesthesiology 125, 1171-1180. doi: 10.1097/aln.0000000000001377

Luan, X., Tian, X., Zhang, H., Huang, R., Li, N., Chen, P. et al. (2019). Exercise as a prescription for patients with various diseases. J. Sport Health Sci. 8, 422-441. doi: 10.1016/j.jshs.2019.04.002

Ma, J., Chen, L., Fan, J., Cao, W., Zeng, G., Wang, Y., et al. (2019). Dualtargeting Rutaecarpine-NO donor hybrids as novel anti-hypertensive agents by promoting release of CGRP. Eur. J. Med. Chem. 168, 146-153. doi: 10.1016/j. ejmech.2019.02.037

Ma, J., Yang, L., Ma, Y., Wang, X., Ren, J., and Yang, J. (2017). Targeting transient receptor potential channels in cardiometabolic diseases and myocardial ischemia reperfusion injury. Curr. Drug Targets 18, 1733-1745.

Ma, Y., Halade, G. V., and Lindsey, M. L. (2012). Extracellular matrix and fibroblast communication following myocardial infarction. J. Cardiovasc. Transl. Res. 5, 848-857. doi: 10.1007/s12265-012-9398-z

Maclay, J. D., and MacNee, W. (2013). Cardiovascular disease in COPD: mechanisms. Chest 143, 798-807.

MacPherson, H. (2007). Acupuncture for hypertension: a tale of two trials. From the perspective of the acupuncturist-MacPherson, York, UK. Forsch Komplementmed 14, 371-373.

MacPherson, L. J., Dubin, A. E., Evans, M. J., Marr, F., Schultz, P. G., Cravatt, B. F., et al. (2007a). Noxious compounds activate TRPA1 ion channels through covalent modification of cysteines. Nature 445, 541-545. doi: 10.1038/ nature 05544

MacPherson, L. J., Xiao, B., Kwan, K. Y., Petrus, M. J., Dubin, A. E., Hwang, S., et al. (2007b). An ion channel essential for sensing chemical damage. J. Neurosci. 27, 11412-11415. doi: 10.1523/jneurosci.3600-07.2007

MacPherson, L. J., Hwang, S. W., Miyamoto, T., Dubin, A. E., Patapoutian, A., and Story, G. M. (2006). More than cool: promiscuous relationships of menthol and other sensory compounds. Mol. Cell Neurosci. 32, 335-343.

Marks, A. R. (2013). Calcium cycling proteins and heart failure: mechanisms and therapeutics. J. Clin. Invest. 123, 46-52.

Massy, Z. A., Metzinger-Le Meuth, V., and Metzinger, L. (2017). MicroRNAs are associated with uremic toxicity, cardiovascular calcification, and disease. Contrib. Nephrol. 189, 160-168.

McNamara, C. R., Mandel-Brehm, J., Bautista, D. M., Siemens, J., Deranian, K. L., Zhao, M., et al. (2007). TRPAl mediates formalin-induced pain. Proc. Natl. Acad. Sci. U.S.A. 104, 13525-13530.

Middlekauff, H. R., Park, J., and Moheimani, R. S. (2014). Adverse effects of cigarette and noncigarette smoke exposure on the autonomic nervous system: mechanisms and implications for cardiovascular risk. J. Am. Coll Cardiol. 64, 1740-1750.

Mokou, M., Lygirou, V., Vlahou, A., and Mischak, H. (2017). Proteomics in cardiovascular disease: recent progress and clinical implication and implementation. Expert Rev. Proteomics 14, 117-136.

Monrad, M., Sajadieh, A., Christensen, J. S., Ketzel, M., Raaschou-Nielsen, O., Tjonneland, A., et al. (2017). Long-term exposure to traffic-related air pollution and risk of incident atrial fibrillation: a cohort study. Environ. Health Perspect. $125,422-427$.

Moran, M. M. (2018). TRP channels as potential drug targets. Annu. Rev. Pharmacol. Toxicol. 58, 309-330.

Moran, M. M., Xu, H., and Clapham, D. E. (2004). TRP ion channels in the nervous system. Curr. Opin. Neurobiol. 14, 362-369.

Mukhopadhyay, I., Kulkarni, A., Aranake, S., Karnik, P., Shetty, M., Thorat, S., et al. (2014). Transient receptor potential ankyrin 1 receptor activation in vitro and in vivo by pro-tussive agents: GRC 17536 as a promising anti-tussive therapeutic. PLoS One 9:e97005. doi: 10.1371/journal.pone.0097005 
Nassini, R., Materazzi, S., Benemei, S., and Geppetti, P. (2014). The TRPA1 channel in inflammatory and neuropathic pain and migraine. Rev. Physiol. Biochem. Pharmacol. 167, 1-43.

Nilius, B., and Owsianik, G. (2011). The transient receptor potential family of ion channels. Genome Biol. 12:218.

Nilius, B., and Szallasi, A. (2014). Transient receptor potential channels as drug targets: from the science of basic research to the art of medicine. Pharmacol. Rev. 66, 676-814.

North, B. J., and Sinclair, D. A. (2012). The intersection between aging and cardiovascular disease. Circ. Res. 110, 1097-1108.

Numazawa, S., Takase, M., Ahiko, T., Ishii, M., Shimizu, S., and Yoshida, T. (2012). Possible involvement of transient receptor potential channels in electrophileinduced insulin secretion from RINm5F cells. Biol. Pharm. Bull. 35, 346-354.

Oguri, G., Nakajima, T., Yamamoto, Y., Takano, N., Tanaka, T., Kikuchi, H., et al. (2014). Effects of methylglyoxal on human cardiac fibroblast: roles of transient receptor potential ankyrin 1 (TRPA1) channels. Am. J. Physiol. Heart Circ. Physiol. 307, H1339-H1352.

Overington, J. P., Al-Lazikani, B., and Hopkins, A. L. (2006). How many drug targets are there? Nat. Rev. Drug Discov. 5, 993-996.

Park, E. O., Bae, E. J., Park, B. H., and Chae, S. W. (2020). The associations between liver enzymes and cardiovascular risk factors in adults with mild dyslipidemia. J. Clin. Med. 9:1147.

Pazienza, V., Pomara, C., Cappello, F., Calogero, R., Carrara, M., Mazzoccoli, G., et al. (2014). The TRPA1 channel is a cardiac target of mIGF-1/SIRT1 signaling. Am. J. Physiol. Heart Circ. Physiol. 307, H939-H944.

Pei, Z., Zhuang, Z., Sang, H., Wu, Z., Meng, R., He, E. Y., et al. (2014). $\alpha, \beta$-unsaturated aldehyde crotonaldehyde triggers cardiomyocyte contractile dysfunction: role of TRPV1 and mitochondrial function. J. Pharmacol Res. 82, 40-50. doi: 10.1016/j.phrs.2014.03.010

Peixoto-Neves, D., Soni, H., and Adebiyi, A. (2019). CGRPergic nerve TRPA1 channels contribute to epigallocatechin gallate-induced neurogenic vasodilation. ACS Chem. Neurosci. 10, 216-220.

Perez, C. M., Hazari, M. S., and Farraj, A. K. (2015). Role of autonomic reflex arcs in cardiovascular responses to air pollution exposure. Cardiovasc. Toxicol. 15, 69-78.

Perkins, J. M., Joy, N. G., Tate, D. B., and Davis, S. N. (2015). Acute effects of hyperinsulinemia and hyperglycemia on vascular inflammatory biomarkers and endothelial function in overweight and obese humans. Am. J. Physiol. Endocrinol. Metab. 309, E168-E176.

Petrus, M., Peier, A. M., Bandell, M., Hwang, S. W., Huynh, T., Olney, N., et al. (2007). A role of TRPA1 in mechanical hyperalgesia is revealed by pharmacological inhibition. Mol. Pain 3:40.

Pozsgai, G., Bodkin, J. V., Graepel, R., Bevan, S., Andersson, D. A., and Brain, S. D. (2010). Evidence for the pathophysiological relevance of TRPA1 receptors in the cardiovascular system in vivo. Cardiovasc. Res. 87, 760-768.

Qian, X., Francis, M., Solodushko, V., Earley, S., and Taylor, M. S. (2013). Recruitment of dynamic endothelial $\mathrm{Ca} 2+$ signals by the TRPA1 channel activator AITC in rat cerebral arteries. Microcirculation 20, 138-148.

Rafehi, H., Ververis, K., and Karagiannis, T. C. (2012). Controversies surrounding the clinical potential of cinnamon for the management of diabetes. Diabetes Obes Metab. 14, 493-499.

Ramkumar, S., Raghunath, A., and Raghunath, S. (2016). Statin therapy: review of safety and potential side effects. Acta Cardiol. Sin. 32, 631-639.

Ramsey, I. S., Delling, M., and Clapham, D. E. (2006). An introduction to TRP channels. Annu. Rev. Physiol. 68, 619-647.

Rhoden, A., Speiser, J., Geertz, B., Uebeler, J., Schmidt, K., De Wit, C., et al. (2019). Preserved cardiovascular homeostasis despite blunted acetylcholine-induced dilation in mice with endothelial muscarinic M3 receptor deletion. Acta Physiol. 226:e13262.

Roe, A. T., Frisk, M., and Louch, W. E. (2015). Targeting cardiomyocyte Ca2+ homeostasis in heart failure. Curr. Pharm. Des. 21, 431-448.

Russell, F. A., King, R., Smillie, S. J., Kodji, X., and Brain, S. D. (2014). Calcitonin gene-related peptide: physiology and pathophysiology. Physiol. Rev. 94, 10991142.

Sahu, A., Jha, P. K., Prabhakar, A., Singh, H. D., Gupta, N., Chatterjee, T., et al. (2017). MicroRNA-145 impedes thrombus formation via targeting tissue factor in venous thrombosis. EBioMedicine 26, 175-186.
Sala, L., and Bellin, M. (2017). Integrating cardiomyocytes from human pluripotent stem cells in safety pharmacology: has the time come? Br. J. Pharmacol. 174, 3749-3765.

Sardar, M. R., Saeed, W., and Kowey, P. R. (2016). Antiarrhythmic drug therapy for atrial fibrillation. Heart Fail. Clin. 12, 205-221.

Sartorius, T., Peter, A., Schulz, N., Drescher, A., Bergheim, I., Machann, J., et al. (2014). Cinnamon extract improves insulin sensitivity in the brain and lowers liver fat in mouse models of obesity. PLoS One 9:e92358. doi: 10.1371/journal. pone.0092358

Schaefer, M. (2005). Homo- and heteromeric assembly of TRP channel subunits. Pflugers Arch. 451, 35-42.

Shanks, J., De Morais, S. D. B., Gao, L., Zucker, I. H., and Wang, H. J. (2019). TRPV1 (Transient Receptor Potential Vanilloid 1) cardiac spinal afferents contribute to hypertension in spontaneous hypertensive rat. Hypertension 74, 910-920.

Shen, M. J., and Zipes, D. P. (2014). Role of the autonomic nervous system in modulating cardiac arrhythmias. Circ. Res. 114, 1004-1021.

Shimokawa, H., Sunamura, S., and Satoh, K. (2016). RhoA/Rho-kinase in the cardiovascular system. Circ. Res. 118, 352-366.

Shrestha, N., Bouttefeux, O., Vanvarenberg, K., Lundquist, P., Cunarro, J., Tovar, S., et al. (2018). The stimulation of GLP-1 secretion and delivery of GLP-1 agonists via nanostructured lipid carriers. Nanoscale 10, 603-613.

Sinha, S., Sinharoy, P., Bratz, I. N., and Damron, D. S. (2015). Propofol causes vasodilation in vivo via TRPA1 ion channels: role of nitric oxide and $\mathrm{BKCa}$ channels. PLoS One 10:e0122189. doi: 10.1371/journal.pone.0122189

Sinharoy, P., Bratz, I. N., Sinha, S., Showalter, L. E., Andrei, S. R., and Damron, D. S. (2017). TRPA1 and TRPV1 contribute to propofol-mediated antagonism of U46619-induced constriction in murine coronary arteries. PLoS One 12:e0180106. doi: 10.1371/journal.pone.0180106

Sousa-Pinto, B., Ferreira-Pinto, M. J., Santos, M., and Leite-Moreira, A. F. (2014). Central nervous system circuits modified in heart failure: pathophysiology and therapeutic implications. Heart Fail. Rev. 19, 759-779.

Story, G. M., Peier, A. M., Reeve, A. J., Eid, S. R., Mosbacher, J., Hricik, T. R., et al. (2003). ANKTM1, a TRP-like channel expressed in nociceptive neurons, is activated by cold temperatures. Cell 112, 819-829.

Sullivan, M. N., Gonzales, A. L., Pires, P. W., Bruhl, A., Leo, M. D., Li, W., et al. (2015). Localized TRPA1 channel Ca2+ signals stimulated by reactive oxygen species promote cerebral artery dilation. Sci. Signal. 8:ra2.

Supowit, S. C., Rao, A., Bowers, M. C., Zhao, H., Fink, G., Steficek, B., et al. (2005). Calcitonin gene-related peptide protects against hypertension-induced heart and kidney damage. Hypertension 45, 109-114.

Sverdlov, A. L., Elezaby, A., Qin, F., Behring, J. B., Luptak, I., Calamaras, T. D., et al. (2016). Mitochondrial reactive oxygen species mediate cardiac structural, functional, and mitochondrial consequences of diet-induced metabolic heart disease. J. Am. Heart Assoc. 5:e002555.

Tabas, I. (2017). 2016 russell ross memorial lecture in vascular biology: molecularcellular mechanisms in the progression of atherosclerosis. Arterioscler. Thromb. Vasc. Biol. 37, 183-189.

Takahashi, N., Chen, H. Y., Harris, I. S., Stover, D. G., Selfors, L. M., Bronson, R. T., et al. (2018). Cancer cells co-opt the neuronal redox-sensing channel trpal to promote oxidative-stress tolerance. Cancer Cell 33, 985.e7-1003.e7.

Talavera, K., Gees, M., Karashima, Y., Meseguer, V. M., Vanoirbeek, J. A., Damann, N., et al. (2009). Nicotine activates the chemosensory cation channel TRPA1. Nat. Neurosci. 12, 1293-1299.

Tamura, Y., Iwasaki, Y., Narukawa, M., and Watanabe, T. (2012). Ingestion of cinnamaldehyde, a TRPA1 agonist, reduces visceral fats in mice fed a high-fat and high-sucrose diet. J. Nutr. Sci. Vitaminol. 58, 9-13.

Taylor-Clark, T. E., Ghatta, S., Bettner, W., and Undem, B. J. (2009). Nitrooleic acid, an endogenous product of nitrative stress, activates nociceptive sensory nerves via the direct activation of TRPA1. Mol. Pharmacol. 75, 820-829.

Taylor-Clark, T. E., Mcalexander, M. A., Nassenstein, C., Sheardown, S. A., Wilson, S., Thornton, J., et al. (2008). Relative contributions of TRPA1 and TRPV1 channels in the activation of vagal bronchopulmonary C-fibres by the endogenous autacoid 4-oxononenal. J. Physiol. 586, 3447-3459.

Thompson, L. C., Walsh, L., Martin, B. L., Mcgee, J., Wood, C., Kovalcik, K., et al. (2019). Ambient particulate matter and acrolein co-exposure increases myocardial dyssynchrony in mice via TRPA1. Toxicol. Sci. 167, 559-572. 
Tian, C., Huang, R., Tang, F., Lin, Z., Cheng, N., Han, X., et al. (2020). Transient receptor potential ankyrin 1 contributes to lysophosphatidylcholine-induced intracellular calcium regulation and THP-1-derived macrophage activation. J. Membr. Biol. 253, 43-55.

Trevisani, M., Siemens, J., Materazzi, S., Bautista, D. M., Nassini, R., Campi, B., et al. (2007). 4-Hydroxynonenal, an endogenous aldehyde, causes pain and neurogenic inflammation through activation of the irritant receptor TRPA1. Proc. Natl. Acad. Sci. U.S.A. 104, 13519-13524.

Ungar, A., Rivasi, G., Petrovic, M., Schonenberger, A., Martinez-Selles, M., Gasowski, J., et al. (2020). Toward a geriatric approach to patients with advanced age and cardiovascular diseases: position statement of the EuGMS Special Interest Group on cardiovascular medicine. Eur. Geriatr. Med. 11, 179-184.

van der Pol, A., Van Gilst, W. H., Voors, A. A., and Van Der Meer, P. (2019). Treating oxidative stress in heart failure: past, present and future. Eur. J. Heart Fail. 21, 425-435.

Vriens, J., Owsianik, G., Voets, T., Droogmans, G., and Nilius, B. (2004). Invertebrate TRP proteins as functional models for mammalian channels. Pflugers Arch. 449, 213-226.

Wang, F., Pu, C., Zhou, P., Wang, P., Liang, D., Wang, Q., et al. (2015). Cinnamaldehyde prevents endothelial dysfunction induced by high glucose by activating Nrf2. Cell Physiol. Biochem. 36, 315-324.

Wang, Q., Chen, K., Zhang, F., Peng, K., Wang, Z., Yang, D., et al. (2020). TRPA1 regulates macrophages phenotype plasticity and atherosclerosis progression. Atherosclerosis 301, 44-53.

Wang, R., Tian, H., Guo, D., Tian, Q., Yao, T., and Kong, X. (2020). Impacts of exercise intervention on various diseases in rats. J. Sport Health Sci. 9, 211-227. doi: 10.1016/j.jshs.2019.09.008

Wang, Z., Xu, Y., Wang, M., Ye, J., Liu, J., Jiang, H., et al. (2018). TRPA1 inhibition ameliorates pressure overload-induced cardiac hypertrophy and fibrosis in mice. EBioMedicine 36, 54-62.

Wang, Z., Ye, D., Ye, J., Wang, M., Liu, J., Jiang, H., et al. (2019). The TRPA1 channel in the cardiovascular system: promising features and challenges. Front. Pharmacol. 10:1253. doi: 10.3389/fphar.2019.01253

Ward, A., Brogden, R. N., Heel, R. C., Speight, T. M., and Avery, G. S. (1983). Amrinone. A preliminary review of its pharmacological properties and therapeutic use. Drugs 26, 468-502.

Watkins, A., Danilewitz, M., Kusha, M., Masse, S., Urch, B., Quadros, K., et al. (2013). Air pollution and arrhythmic risk: the smog is yet to clear. Can. J. Cardiol. 29, 734-741.

Wei, H., Hamalainen, M. M., Saarnilehto, M., Koivisto, A., and Pertovaara, A. (2009). Attenuation of mechanical hypersensitivity by an antagonist of the TRPA1 ion channel in diabetic animals. Anesthesiology 111, $147-154$.

Williams, S. B., Goldfine, A. B., Timimi, F. K., Ting, H. H., Roddy, M. A., Simonson, D. C., et al. (1998). Acute hyperglycemia attenuates endothelium-dependent vasodilation in humans in vivo. Circulation 97, 1695-1701.

Winter, Z., Gruschwitz, P., Eger, S., Touska, F., and Zimmermann, K. (2017). Cold temperature encoding by cutaneous TRPA1 and TRPM8-carrying fibers in the mouse. Front. Mol. Neurosci. 10:209. doi: 10.3389/fnmol.2017.00209

Wu, Z., He, E. Y., Scott, G. I., and Ren, J. (2015). $\alpha, \beta$-unsaturated aldehyde pollutant acrolein suppresses cardiomyocyte contractile function: role of
TRPV1 and oxidative stress. Environ. Toxicol. 30, 638-647. doi: 10.1002/tox. 21941

Wu, N. N., Tian, H., Chen, P., Wang, D., Ren, J., and Zhang, Y. (2019a). Physical exercise and selective autophagy: benefit and risk on cardiovascular health. Cells 8:1436. doi: $10.3390 /$ cells 8111436

Wu, N. N., Zhang, Y., and Ren, J. (2019b). Mitophagy, mitochondrial dynamics, and homeostasis in cardiovascular aging. Oxid. Med. Cell. Longev. 2019:9825061. doi: 10.1155/2019/9825061

Xiao, R., Zhang, B., Dong, Y., Gong, J., Xu, T., Liu, J., et al. (2013). A genetic program promotes $C$. elegans longevity at cold temperatures via a thermosensitive TRP channel. Cell 152, 806-817.

Yu, M., Jiang, M., Chen, Y., Zhang, S., Zhang, W., Yang, X., et al. (2016). Inhibition of Macrophage CD36 Expression and Cellular Oxidized Low Density Lipoprotein (oxLDL) Accumulation by Tamoxifen: a PEROXISOME PROLIFERATOR-ACTIVATED RECEPTOR (PPAR)gamma-DEPENDENT MECHANISM. J. Biol. Chem. 291, 16977-16989.

Yue, Z., Xie, J., Yu, A. S., Stock, J., Du, J., and Yue, L. (2015). Role of TRP channels in the cardiovascular system. Am. J. Physiol. Heart Circ. Physiol. 308, H157-H182.

Yung, B. S., Brand, C. S., Xiang, S. Y., Gray, C. B., Means, C. K., Rosen, H., et al. (2017). Selective coupling of the S1P3 receptor subtype to S1P-mediated RhoA activation and cardioprotection. J. Mol. Cell Cardiol. 103, 1-10.

Zhang, B., Xiao, R., Ronan, E. A., He, Y., Hsu, A. L., Liu, J., et al. (2015). Environmental temperature differentially modulates C. elegans Longevity through a Thermosensitive TRP Channel. Cell Rep. 11, 1414-1424.

Zhang, Y., Li, L., Hua, Y., Nunn, J. M., Dong, F., Yanagisawa, M., et al. (2012). Cardiac-specific knockout of ET(A) receptor mitigates low ambient temperature-induced cardiac hypertrophy and contractile dysfunction. J. Mol. Cell Biol. 4, 97-107.

Zhao, J. F., Shyue, S. K., Kou, Y. R., Lu, T. M., and Lee, T. S. (2016). Transient receptor potential ankyrin 1 channel involved in atherosclerosis and macrophage-foam cell formation. Int. J. Biol. Sci. 12, 812-823.

Zheng, H., Whitman, S. A., Wu, W., Wondrak, G. T., Wong, P. K., Fang, D., et al. (2011). Therapeutic potential of Nrf2 activators in streptozotocin-induced diabetic nephropathy. Diabetes 60, 3055-3066.

Zheng, X. L., Yuan, S. G., and Peng, D. Q. (2007). Phenotype-specific inhibition of the vascular smooth muscle cell cycle by high glucose treatment. Diabetologia 50, 881-890.

Zhong, J., Pollastro, F., Prenen, J., Zhu, Z., Appendino, G., and Nilius, B. (2011). Ligustilide: a novel TRPA1 modulator. Pflugers Arch. 462, 841-849.

Conflict of Interest: The authors declare that the research was conducted in the absence of any commercial or financial relationships that could be construed as a potential conflict of interest.

Copyright (c) 2020 Gao, Kaudimba, Guo, Zhang, Liu, Chen and Wang. This is an open-access article distributed under the terms of the Creative Commons Attribution License (CC BY). The use, distribution or reproduction in other forums is permitted, provided the original author(s) and the copyright owner(s) are credited and that the original publication in this journal is cited, in accordance with accepted academic practice. No use, distribution or reproduction is permitted which does not comply with these terms. 